\title{
Testing the cycle of maltreatment hypothesis: Meta-analytic evidence of the intergenerational transmission of child maltreatment
}

\author{
SHERI MADIGAN, ${ }^{a, b}$ CHANTAL CYR,${ }^{c, d}$ RACHEL EIRICH, ${ }^{a}$ R. M. PASCO FEARON,${ }^{e}$ ANH LY, ${ }^{a}$ \\ CHRISTINA RASH, ${ }^{a}$ JULIA C. POOLE, ${ }^{a}$ AND LENNEKE R. A. ALINK ${ }^{f}$ \\ ${ }^{a}$ University of Calgary; ${ }^{b}$ Alberta Children's Hospital Research Institute, Calgary; ${ }^{c}$ Université du Québec à Montréal; ${ }^{d}$ Institut \\ Universitaire Jeunes en Difficulté CIUSSS Centre-Sud-de-l'île-de-Montréal; ${ }^{e}$ University College London; and ${ }^{f}$ Leiden University
}

\begin{abstract}
It has long been claimed that "maltreatment begets maltreatment," that is, a parent's history of maltreatment increases the risk that his or her child will also suffer maltreatment. However, significant methodological concerns have been raised regarding evidence supporting this assertion, with some arguing that the association weakens in samples with higher methodological rigor. In the current study, the intergenerational transmission of maltreatment hypothesis is examined in 142 studies (149 samples; 227,918 dyads) that underwent a methodological quality review, as well as data extraction on a number of potential moderator variables. Results reveal a modest association of intergenerational maltreatment $(k=80 ; d=0.45,95 \%$ confidence interval; CI [0.37, 0.54$]$ ). Support for the intergenerational transmission of specific maltreatment types was also observed (neglect: $k=13, d=0.24,95 \%$ CI [0.11, 0.37]; physical abuse: $k=61, d=0.41,95 \%$ CI [0.33, 0.49]; emotional abuse: $k=18, d=0.57,95 \%$ CI [0.43, 0.71]; sexual abuse: $k=18, d=0.39,95 \%$ CI [0.24, 0.55$]$ ). Methodological quality only emerged as a significant moderator of the intergenerational transmission of physical abuse, with a weakening of effect sizes as methodological rigor increased. Evidence from this meta-analysis confirms the cycle of maltreatment hypothesis, although effect sizes were modest. Future research should focus on deepening understanding of mechanisms of transmission, as well as identifying protective factors that can effectively break the cycle of maltreatment.
\end{abstract}

Considerable research over the past half century has been devoted to understanding the determinants and long-term consequences of child maltreatment. Interest in this phenomenon was sparked by the ground-breaking work of Kempe, Silverman, Steele, Droegemueller, and Silver (1962) on battered child syndrome, which inspired researchers and the medical community to recognize child maltreatment as a serious public health and social problem. Since their seminal publication, generations of researchers from a wide range of disciplines have attempted to investigate the extent of the problem, as well as its antecedent risks, social impact, and psychological outcomes, in order to mitigate its occurrence via preventive interventions.

The burden of maltreatment for children, families, and society more broadly is astounding. Per nonfatal child maltreatment victim in the United States, the average lifetime cost is estimated at $\$ 210,012$, and the total lifetime economic burden resulting from new cases of maltreatment in 2008 was estimated to be $\$ 124$ billion (Fang, Brown, Florence, \& Mercy, 2012). This burden can be passed on from generation

Address correspondence and reprint requests to: Sheri Madigan, Department of Psychology, University of Calgary, 2500 University Ave., Calgary, AB, T2N 1N4; E-mail: sheri.madigan@ucalgary.ca. to generation; there is evidence that childhood maltreatment experiences increase the risk of maltreating parenting (Pears \& Capaldi, 2001; Savage, Tarabulsy, Pearson, Collin-Vézina, \& Gagné, 2019; Widom, Czaja, \& DuMont, 2015). However, results of existing empirical studies are inconsistent and sometimes contradictory. Therefore, the current study presents a series of comprehensive meta-analyses on the intergenerational transmission of maltreatment in general, as well as specific maltreatment types.

Based on the results of an expert international panel convened to consult on child maltreatment prevention, the World Health Organization (WHO; 1999) offers the following definition: "Child abuse or maltreatment constitutes all forms of physical and/or emotional ill-treatment, sexual abuse, neglect or negligent treatment or commercial or other exploitation, resulting in actual or potential harm to the child's health, survival, development or dignity in the context of a relationship of responsibility, trust or power." This broad definition encompasses a wide spectrum of behaviors, from severe acts of physical abuse to arguably more hidden forms of maltreatment such as emotional neglect. Given the wide range of parenting practices, cultural expectations, and differing views on what constitutes child maltreatment, the WHO's definition is especially expedient as it offers a standard definitional tool 
with which to assess potentially abusive and neglectful behavior. In this paper, following the definition set out by the WHO, we use the term child maltreatment to reflect the wide range of abusive, neglectful, and/or harmful behaviors experienced by children. ${ }^{1}$

Population-based surveys undertaken in different countries, along with national statistics compiled through reports to state and local child protective service agencies, reveal that the prevalence of child maltreatment is a global health problem of epidemic proportions. Specifically, several meta-analyses have reported on the worldwide prevalence of childhood maltreatment, with mean prevalence rates for sexual abuse reported to be $12.7 \%$ (Stoltenborgh, van IJzendoorn, Euser, \& Bakermans-Kranenburg, 2011), 26.7\% for emotional abuse (Stoltenborgh, Bakermans-Kranenburg, Alink, \& van IJzendoorn, 2012), 17.7\% for physical abuse (Stoltenborgh, Bakermans-Kranenburg, van Ijzendoorn, \& Alink, 2013), and $16.3 \%$ and $18.4 \%$ for physical and emotional neglect, respectively (Stoltenborgh, Bakermans-Kranenburg, \& van IJzendoorn, 2013).

The vast literature on child maltreatment unambiguously demonstrates its deleterious consequences. In a commissioned report by the US National Research Council (1993), the Panel on Research on Child Abuse and Neglect identified four primary areas in which the consequences of childhood maltreatment are known to have devastating effects. Organized according to a developmental framework, these areas include: medical and physiological consequences; cognitive and intellectual consequences; psychosocial consequences; and behavioral consequences. Medical and physiological consequences can include head trauma, failure to thrive, growth deficiencies, obesity, and other neuromotor handicaps (Danese \& Tan, 2014; Norman et al., 2012). Cognitive and intellectual consequences of childhood maltreatment can include reduced cognitive functioning, impaired language development, and other neurological dysfunctions (Harden, Buhler, \& Parra, 2016; Pollak et al., 2010). Maltreated children are at a greater risk for developmental delay, and the psychosocial consequences are numerous, including poorer social skills and increased risk for mental health problems (Vachon, Krueger, Rogosch, $\&$ Cicchetti, 2015). Finally, the effects of childhood maltreatment on psychopathology have been extensively researched, with results showing that maltreated children exhibit higher rates of physical aggression, antisocial behavior, delinquency, problematic internalizing and externalizing behaviors, and other risky behaviors (Hughes et al., 2017; Norman et al., 2012; Vachon et al., 2015).

Theoretical models suggest that multiple factors and layered contexts can contribute to family and interpersonal violence in general, and child maltreatment in particular. The notion proposed decades ago by Garbarino and Gilliam (1980), "the premier developmental hypothesis in the field of abuse and neglect is the notion of intergenerational transmis-

1. We use the term child abuse in some instances only when the authors of studies we cite employ this term themselves. sion, the idea that abusing parents were themselves abused as children and that neglect breeds neglect" (p. 111), remains today. The common assumption that violence breeds violence (Curtis, 1963) has been extensively discussed in the literature and posited as the "cycle of maltreatment" hypothesis (Thornberry, Knight, \& Lovegrove, 2012). ${ }^{2}$ To date, the extensive body of literature on this phenomenon comprises two approaches from which to conceptualize the behaviors and risk factors for the cycle of maltreatment. One conceptual approach posits that maltreated children are likely to become abusive parents. This victim-to-perpetrator conceptual approach is analogous to the "cycle of violence" hypothesis put forth by Widom (1989) and is the most common paradigm evoked in discussions of the direct intergenerational transmission of maltreatment. Another related approach suggests that individuals who are victims of childhood maltreatment go on to have children of their own who are also likely to experience maltreatment, even though they may not be the perpetrators of that maltreatment themselves. This victimto-victim conceptual approach highlights the indirect transmission of maltreatment and is supported by a body of literature that focuses on the transmission of maltreatment victimization experiences without distinguishing actual abusers from nonoffending caregivers (Kim, Noll, Putnam, \& Trickett, 2007). The transmission of sexual abuse, for example, may involve a parent who was sexually victimized as a child and subsequently becomes more likely to have a child who experiences sexual abuse himself/herself, at the hands of someone other than the victimized parent. These two conceptual approaches, which are known to have common risk factors (e.g., poverty, substance use, mental health difficulties, adolescent parenthood, and parenting stress), are often collectively examined under the umbrella hypothesis of "the intergenerational transmission of maltreatment" (Brown, Cohen, Johnson, \& Salzinger, 1998; Dixon, Browne, \& Giachritsis, 2005; Shenk et al., 2017; Stith et al., 2009).

A comprehensive meta-analysis of the empirical studies amassed to date, along with an assessment of study quality, and an investigation of whether study quality moderates the magnitude of the intergenerational transmission of maltreatment, broadly conceptualized, is needed to move the field forward into its next half century of research. Relatedly, we also examine homotypic or heterotypic transmission of maltreatment (Berzenski, Yates, \& Egeland, 2014). Homotypic transmission refers to the perpetuation of specific types of child maltreatment experience. For example, is a mother who was physically abused as a child more likely to have a child who experiences physical abuse? Does neglect beget neglect? Heterotypic transmission examines whether being the victim of a specific type of maltreatment increases the likelihood of perpetuating other types of maltreatment experiences. For ex-

2. Other associated terms include "cycle of violence," the "intergenerational transmission of abuse" (Kaufman \& Zigler, 1989), the "intergenerational transmission of maltreatment," or the "continuity of child maltreatment" (Dixon, Browne, \& Hamilton-Giachritsis, 2005). 
ample, is a mother who was physically abused as a child more likely to have a child who experiences neglect? In such cases, the child and mother are both victims of maltreatment, but of different forms (Berzenski et al., 2014). Berzenski et al. (2014) have argued that both transmission types should be examined, to ensure that information about the form and/or function of these transmission methods can be garnered.

\section{Methodological Considerations and Controversies}

Although the bulk of research has generally found evidence in support of the intergenerational maltreatment hypothesis, the association is not ubiquitous, and the strength of this association varies across studies even with similar sample characteristics. For instance, a study by Appleyard, Berlin, Rosanbalm, and Dodge (2011) on 499 mother-child dyads from a small southeastern city in the United States found that maternal history of childhood physical abuse weakly predicted offspring victimization. In contrast, research by Simons, Whitbeck, Conger, and Wu (1991) on 451 parent-child dyads from Northern Iowa found a substantially larger effect for the intergenerational transmission of physical abuse. Variations in effect sizes can be due to a number of methodological issues, as many researchers have suggested (Heller, Larrieu, D'Imperio, \& Boris, 1999; Thornberry et al., 2012). Today, considerable controversy exists regarding the role of methodology in supporting or refuting the intergenerational transmission of maltreatment hypothesis. Decades ago, Garbarino and Gilliam (1980) noted that this intuitively appealing hypothesis has not "passed scientific muster" (p. 111), an opinion that has been proliferated in the literature over time (Thornberry et al., 2012; Widom, 1989). Specifically, the validity of findings has been questioned due to several important methodological limitations and biases, including the use of poor operational definitions of maltreatment, retrospective recall, single informants for the assessment of maltreatment in different generations, and an absence of prospective studies.

One study that exemplifies methodological rigor in the field, is by Widom et al. (2015). They prospectively followed 902 children with documented cases of maltreatment having occurred between 1967 and 1971, with a matched comparison group $(N=667)$. These participants were followed for a period of approximately 40 years, and the Child Protective Services (CPS) agency records of these individuals and their children were searched during this time. Using a multi-informant, multi-method approach to assessing maltreatment, the authors found that approximately $21 \%$ of parents with documented histories of maltreatment perpetrated some form of maltreatment toward their own children, compared to $11.7 \%$ of matched comparisons (adjusted odds ratio: 2.01; $95 \%$ confidence interval; CI $[1.42,2.85])$. They also found that parents with a history of maltreatment were approximately four times more likely than matched controls to have a child placed in the custody of the courts $(4.8 \%$ vs.
$1.3 \%$ ). However, the extent of intergenerational transmission varied as a function of the type of maltreatment being perpetrated: a parent's history of sexual abuse was associated with a twofold increased risk of their child being sexually abused, a history of neglect was associated with a twofold increased risk of perpetuation of neglect, but a history of physical abuse was not associated with an increased risk of propagating physical abuse. Thus, based on best quality methodology, the authors concluded that the strongest evidence for intergenerational transmission of maltreatment is for sexual abuse and neglect.

Several methodological reviews of the intergenerational transmission hypothesis have been published. In a review of 20 studies, Kaufman and Zigler (1987) asserted that, despite the widely accepted public and professional opinion that maltreated children become maltreating parents, there was a dearth of high-quality empirical evidence supporting this notion. As a result, they critically reviewed all methods of testing this assumption to determine its scientific validity. They concluded that the "best estimate" of the rate of intergenerational transmission of maltreatment was approximately $30 \%$ ( $\pm 5 \%$ ), a rate five times the size of the base rate for maltreatment in the general population. However, they determined that many studies lacked methodological substantiation and rigor to support theoretical assumptions. The authors concluded that there is some evidence to support the notion that maltreatment is transmitted across generations; however, they also stated that unqualified acceptance of this hypothesis is not only unfounded, but misguided.

In a review of 10 studies on the intergenerational transmission of physical abuse in particular, ${ }^{3}$ published between 1965 and 2000, Ertem, Leventhal, and Dobbs (2000) examined the scientific validity by delineating a set of eight methodological standards, the most salient of which included the following: adequate definitional criteria and demographic comparability, avoidance of recall and detection bias via retrospective measurement, double-blind evaluators of parent and child history of physical abuse, and controls for potential intervening variables. The authors noted that their criteria were poorly met: $80 \%$ of studies met fewer than five methodological standards. Accordingly, the authors concluded that there was little robust evidence that a history of being physically abused leads to perpetuating physical abuse. They suggested that further investigation was needed in order to deepen knowledge and to derive concrete conclusions on the purported generational continuity of physical abuse.

Following the publication of Ertem et al.'s (2000) review, the notion that maltreatment begets maltreatment continued to be debated in the scientific literature and public domain. Many methodologically rigorous studies on the topic were

3. Although the literature on the intergenerational transmission of maltreatment is quite large, the comparatively smaller sample size in the Ertem et al. review was due to their stringent criteria for study inclusion (e.g., a comparison group was required) and an exclusive focus on physical abuse. 
published, but debate on the validity of these studies has continued to be questioned. In 2012, Thornberry et al. provided an updated methodological review of the literature on the intergenerational transmission of maltreatment. They drew on the work of Ertem et al. (2000), but examined the broader category of maltreatment rather than limiting their analysis to physical abuse only, and elaborated on their review via an expanded set of 11 methodological standards (see Table 1). In total, 47 studies were scored using these methodological standards, and no study met all 11 methodological criteria (mean score: 4.81 ; range: $2-10$ ). Among the 7 studies considered to be of highest methodological quality, 2 found direct and 1 found indirect support (via mediated pathways) for the intergenerational maltreatment hypothesis, 3 found support for sexual and/or physical abuse transmission in particular, but not maltreatment more broadly, and 1 failed to find support for the intergenerational transmission of maltreatment hypothesis. Of the 24 studies that were deemed to have only modest methodological quality, 20 had significant effect sizes. The authors concluded that, although most studies found weak to modest support for the cycle of maltreatment hypothesis, evidence from their review suggests that in studies with more rigorous methodology, this support becomes tenuous.

\section{The Current Study}

All reviews to date have provided either a narrative review of the literature and/or its methodological approaches, or a methodological quality evaluation, and subsequent description of

Table 1. Study quality indicators

\section{Description
1. Sample that is representative of a general population or uses
random sampling techniques.}

2. Satisfactory participation or attrition rates.

3. Maltreated and nonmaltreated individuals included in the primary sample.

4. Attempt was made to confirm the nonmaltreatment status in the comparison group.

5. Controls for potential confounding factors or matching in studies comparing maltreated and nonmaltreated groups.

6. Prospective measure of maltreatment (G2).

7. Prospective measure of maltreatment (G3).

8. Multiple reporters of maltreatment for each generation.

9. Same follow-up/exposure period for maltreated and nonmaltreated groups.

10. Follow-up/exposure period of an adequate timeframe.

11. Valid measures used to assess maltreatment (G2).

12. Valid measures used to assess maltreatment (G3).

13. Maltreatment clearly defined beyond a description of the measures used in the study.
Code

$0=N o$

$1=$ Yes

$0=$ Unacceptable (participation less than $60 \%$ or attrition greater than $40 \%$ )

$1=$ Acceptable (participation greater than $60 \%$ or attrition under $40 \%)$

$0=N o$

$1=$ Yes

$0=N o$

$1=$ Yes

$0=N o$

$1=$ Yes

$0=$ Retrospective

$1=$ Prospective

$0=$ Retrospective

$1=$ Prospective

$0=$ Single (only one respondent reported abuse in both generations)

$1=$ Multiple (abuse records based on two official sources or both generations' self-reports, etc.)

$0=N o$

$1=$ Yes

$0=$ Low $($ children $<5$ years old $)$

$1=$ Adequate (children $>5$ years)

$0=$ Not validated (i.e., the researchers made up a question to ask participants)

1 = Official (based on official documents, e.g., court records or CPS) or Validated (CTS, CTQ, etc.)

$0=$ Not validated (i.e., the researchers made up a question to ask participants)

$1=$ Official (based on official documents, e.g., court records or CPS) or Validated (CTS, CTQ, etc.)

$0=$ Not clearly defined

$1=$ Clearly defined

Note: Study quality indicators adapted from Thornberry et al. (2012). CPS = Child Protective Services; CTS = Conflict Tactics Scale; CTQ= Childhood Trauma Questionnaire; G2 = parent generation; G3 = child generation. 
the number of studies (so-called vote counting) reporting statistically significant intergenerational transmission of maltreatment stratified by levels of predetermined methodological validity (Ertem et al., 2000; Thornberry et al., 2012). While both approaches have merit in the field and likely collectively spurred more methodologically rigorous research, there are limitations to drawing conclusions based purely on a count of the number of studies reporting statistical significance alone. The $p$ value is highly dependent on statistical power, and studies differing widely in their substantive findings may be treated inaccurately as yielding the same evidence. Further, such vote counting does not allow for the estimation of the overall strength of the observed associations, the extent to which findings are consistent across studies or vary systematically from one another (i.e., between-study heterogeneity), the sources of such between-study variation, or the impact of publication bias. By combining studies via a meta-analysis, the shortcomings of narrative and methodological quality reviews can be overcome by the calculation of an overall effect size estimate of the intergenerational transmission of maltreatment that corrects for biases that can accompany small sample sizes, addresses potential publication bias, and identifies important study characteristics potentially responsible for differing estimates of intergenerational association (Valentine, Pigott, \& Rothstein, 2010). Examining whether study characteristics impact the strength of the observed association between maltreatment across generations is critically important in this context because it allows a clear test for the presence of upward bias associated with low-quality studies.

In the current meta-analytic synthesis, Thornberry et al.'s (2012) methodological standards were used to examine methodological quality as a moderator in all studies meeting study inclusion (see Table 1). In addition, critical to adequately exploring the strength of the intergenerational maltreatment literature is an examination of differences that may arise as a result of how maltreatment measures are collected, and who is providing the information on the maltreatment experiences. These measurement factors go beyond what may be measured as methodological quality, as one method of collecting data is not necessarily deemed to be more rigorous in terms of methodological strength, but effect sizes may, nonetheless, vary by these measurement factors and thus they are worthy of examination.

\section{Measurement factors}

Studies that rely on self-report methodology typically use interviews and questionnaires. Other studies use case records, such as CPS case files or other official reports (i.e., hospital records). Each method of collecting information has its own set of strengths and weaknesses that could influence effect size estimates. Questionnaires and face-to-face interviews are based on retrospective recall of maltreatment experiences, which can lead to underreporting and may fail to adequately capture the chronicity and severity of maltreatment experi- ences (Henry, Moffitt, Caspi, Langley, \& Silva, 1994). Another method of data collection is through case reviews. A potential drawback of case reviews is that they are based on reported incidents and/or substantiated maltreatment cases that have, for example, fallen under the purview of child protective services, which can underestimate the true occurrence of maltreatment (Leventhal, 1998), and can also lead to detection bias (Widom \& Wilson, 2015).

Studies examining the worldwide prevalence of various types of maltreatment experiences have found large between-study differences based on the type of measure and informant of maltreatment (Stoltenborgh et al., 2011), with informant reports resulting in lower prevalence estimates than self-report. In the intergenerational transmission of maltreatment literature, some studies have noted that effect sizes may be more robust using case reviews (Bartlett, Kotake, Fauth, \& Easterbrooks, 2017; Milaniak \& Widom, 2015; Wekerle, Wall, Leung, \& Trocmé, 2007), while others have not (Healy, Kennedy, \& Sinclair, 1991; Tomison, 1994). Finally, some studies use mixed informants, such as self-report for the parent or second generation (G2) maltreatment who were maltreated by the grandparent or first generation (G1), and case reports for the child or third generation (G3). This mixed-informant approach disentangles potential informant bias that can accompany parent reports of both G2 and G3 maltreatment. Taken together, it is crucial to determine if estimates of intergenerational transmission significantly vary according to the method of collecting maltreatment experiences (examined as type of measures and type of informant of maltreatment experiences).

In addition to testing for methodological quality and measurement factors, the current study tests a set of moderators that may also affect the strength of the intergenerational association, including the role of poverty and family risk, child age and gender, as well as publication bias and dissemination medium.

Demographic Risks. Although child maltreatment cuts across all ethnicities and socioeconomic strata (SES), the prevalence of maltreatment has been shown to be higher in minority populations and/or in groups characterized as having low SES (Hussey, Chang, \& Kotch, 2006; Sedlak et al., 2010; Stith et al., 2009). SES can be conceptualized as a contextual indicator for other factors that may increase the risk of committing child maltreatment, such as parental psychopathology and early childbearing (Pears \& Capaldi, 2001). These contextual indicators may impinge on or interfere with educational and employment opportunities and lead to low SES or poverty, and the financial and contextual stressors typically associated with them (Miech, Caspi, Moffitt, Wright, \& Silva, 1999). For example, early childbearing is associated with poor educational attainment, which, in turn, limits employment opportunities (Assini-Meytin \& Green, 2015; Taylor, 2009). The possibility that the intergenerational transmission of maltreatment varies according to SES is suggested by a number of studies that have reported that low SES families, 
as well as minority populations (Pelton, 2015), are exposed to greater social stressors, including financial strain, frequent moves, community violence, and single parenthood, that place them at higher risk of child maltreatment (Alink, Euser, van IJzendoorn, \& Bakermans-Kranenburg, 2013). In effect, a parent's own history of maltreatment, plus the additional strain of poverty and its correlates, can serve as a potent "double threat" that increases the risk of the perpetuation of child maltreatment (Hughes, Parkinson, \& Vargo, 1989). As a result, in the current study we examine several factors related to family risk as potential moderators of the intergenerational transmission of maltreatment.

Child age and gender. The definition of child maltreatment encompasses experiences endured from birth to 18 years (WHO, 2001), although maltreatment experiences are most likely to occur between birth to age 5 (US Department of Health and Human Services, 2014), and are much less likely to occur after the age of 15 (Thornberry, Ireland, \& Smith, 2001). Child age, as it pertains to the intergenerational transmission of maltreatment, is a relevant moderator, as studies examining this association within a short exposure time (e.g., when G3 is age 3) may underestimate the prevalence of G3 maltreatment and, therefore, misrepresent the association of intergenerational transmission (Thornberry et al., 2012), whereas studies examining child maltreatment when children are older may have larger effect sizes due the possibly longer period of potential exposure. As a result, we examine whether child age explains between-study heterogeneity of effect sizes.

Child sexual abuse is asymmetric between boys and girls: the prevalence is $18.0 \%$ for girls and $7.6 \%$ for boys (Stoltenborgh et al., 2012). In contrast, the prevalence rates of physical and emotional abuse, as well as neglect, are similar for boys and girls (Stoltenborgh, Bkermans-Kranenburg, \& van IJzendoorn, 2013; Stoltenborgh, Bkermans-Kranenburg, van IJzendoorn, et al., 2013). Similarly, the only clear pattern of gender differences to have emerged in the intergenerational transmission literature is that the transmission of child sexual abuse is more likely for girls, than for boys (e.g., McCloskey \& Bailey, 2000).

Publication status, sample size, and study year. Effect sizes can differ based on publication status and year of data collection. In comparison to unpublished studies (e.g., dissertations and book chapters), published studies undergo the rigors of the peer-review process, which includes evaluation of the substantive contributions and methodological quality of the research. However, such studies may also be biased in favor of larger effect sizes and statistical significance (e.g., Verhage et al., 2016). It is thus critical, where possible, to include data from both published and unpublished sources. Another important source of potential bias is the year of publication, as it is well known that early studies, often relying on weaker methods, tend to produce larger effect sizes (Ioannidis, 2005). In the field of maltreatment research, early examination of the intergenerational hypothesis was conducted in studies with small sample sizes, limited diversity, and no statistical controls, which can influence the magnitude of associations. More recent studies have tended to be methodologically more rigorous, involving large sample sizes, and accounting for potential study confounds. Thus, study sample size is also examined as a potential moderator of associations.

In sum, this study aimed to resolve discrepancies and debates in the field of child maltreatment by synthesizing the literature meta-analytically and testing moderating variables that may amplify or attenuate associations of intergenerational maltreatment. To evaluate risk of methodological bias, we assessed the methodological quality of each study included in the meta-analysis based on predetermined methodological standards, and tested whether methodological quality at the individual-study level impacts the strength of intergenerational transmission. This is a critical endeavor, as an examination of mechanisms of intergenerational transmission has been hampered by a lack of resolution of this methodological controversy, and clear evidence regarding the status of this profoundly important question remains ambiguous.

\section{Method}

\section{Definitional criteria of maltreatment}

Definitional criteria for the constructs of the meta-analysis were guided by the international Consultation of Child Abuse Prevention (WHO, 1999). ${ }^{4}$ In this consultation, physical abuse was defined as "that which results in actual or potential physical harm from an interaction or lack of an interaction, which is reasonably within the control of a parent or person in a position of responsibility, power or trust" (p. 15). Neglect was defined as "the failure to provide for the development of the child in all spheres: health, education, emotional development, nutrition, shelter, and safe living conditions, in the context of resources reasonably available to the family or caretakers and causes or has a high probability of causing harm to the child's health or physical, mental, spiritual, moral or social development. This includes the failure to properly supervise and protect children from harm as much as is feasible" (p. 15). Sexual abuse was defined as "the involvement of a child in sexual activity that he or she does not fully comprehend, is unable to give informed consent to, or for which the child is not developmentally prepared and cannot give consent, or that violate the laws or social taboos of society" (p. 15). Emotional or psychological abuse (henceforth referred to as emotional abuse), is defined as "the failure to pro-

4. In studies that did not explicitly label their maltreatment measure as "emotional abuse," "physical abuse," "sexual abuse," or "neglect," an inference was made if the measure examined behaviors in line with the definitions above. If a study combined maltreating and nonmaltreating behaviors in their measure of, for example, "emotional abuse" (e.g., displays of negative affect, expressions of anger, scolding, irritability, demandingness, immaturity, self-centeredness, poor discipline, etc.), it was excluded. 
vide a developmentally appropriate, supportive environment, including the availability of a primary attachment figure, so that the child can develop a stable and full range of emotional and social competencies commensurate with her or his personal potentials and in the context of the society in which the child dwells. There may also be acts towards the child that cause or have a high probability of causing harm to the child's health or physical, mental, spiritual, moral or social development. These acts must be reasonably within the control of the parent or person in a relationship of responsibility, trust or power. Acts include restriction of movement, patterns of belittling, denigrating, scapegoating, threatening, scaring, discriminating, ridiculing or other non-physical forms of hostile or rejecting treatment" (WHO, 1999, p. 15).

\section{Search strategy}

Searches were conducted in MEDLINE, EMBASE, PsycINFO, Social Work Abstracts, Web of Science, and the Cochrane Central Register of Controlled Trials in June 2015 and updated in April 2018. Both database subject heading fields (e.g., MeSH in MEDLINE and Emtree in Embase) and text word fields were searched for the concept of maltreatment (including physical, sexual, emotional, psychological, verbal, and neglect; see Appendix A). Text word fields were searched to capture the concept of intergenerational maltreatment. Synonymous terms were combined with the Boolean "OR." These two concepts of maltreatment and intergenerational abuse were combined with the Boolean "AND." Age was searched through a combination of database limits, subject headings, and text word searching. In all databases, truncation symbols and adjacency operators were used in text word searches when appropriate, to capture variations in spelling and phrasing. A second method of searching included the review of the reference lists of relevant reviews, articles, and book chapters. The database search yielded 2,100 relevant nonduplicate records, and an additional 126 abstracts were manually searched via the review of reference lists, leading to a combined total of 2,226 records (see Figure 1).

\section{Inclusions and exclusion criteria}

Studies were deemed to meet inclusion based on the following criteria: (a) included a measure of childhood maltreatment (physical, sexual, emotional abuse, and/or neglect) among the parental generation ( $\mathrm{G} 2$ abused by their G1 parental figure); (b) included an outcome measure of child maltreatment among the G3 generation; (c) child maltreatment experienced by G2 and G3 occurred at $\leq 18$ years of age; (d) maltreatment was measured via self-report, interviews, official CPS records, or equivalent child authority records; (e) sufficient information was provided for the calculation of an effect size; and (f) the study was written in English, French, or Spanish.

Exclusion criteria included the following: (a) nonempirical publications, such as descriptive reports, case studies, or book and narrative reviews; (b) studies examining the asso- ciation between witnessing interparental violence and violent behavior in adolescence/adulthood (Stith et al., 2000) or violence exposure/abuse victimization in childhood and risks for committing intimate partner violence in adulthood (Wilson, Stover, \& Berkowitz, 2009); (c) studies on posttraumatic stress disorder from war, genocide, or other traumatic historical events and risk of perpetuating maltreatment; and (d) studies examining potential for, but not perpetration of, maltreatment (e.g., studies using the Child Abuse Potential Inventory; Milner, 1986).

All records were reviewed by at least two graduate research assistants, and the full text article of any study deemed to potentially meet inclusion criteria was examined. Using the specified inclusion and exclusion criteria, 424 records met initial inclusion criteria and their full text articles were retrieved, and 1,802 were excluded. Upon thorough review of 424 full text articles, a subsequent 282 studies did not meet our inclusion criteria (see Figure 1). Thus, the total number of studies included in the current meta-analysis was 142 studies with 149 samples, and the $k$ for each maltreatment type was as follows: G2 maltreatment - $>\mathrm{G} 3$ maltreatment $k=80$; G2 neglect $->\mathrm{G} 3$ neglect $k=13$; G2 physical abuse $->\mathrm{G} 3$ physical abuse $k=61$; G2 emotional abuse $->\mathrm{G} 3$ emotional abuse $k=18$; G2 sexual abuse -> G3 sexual abuse $k=18$.

\section{Data extraction: Methodological review}

As detailed in Table 1, the same methodological criteria used in Thornberry et al.'s, (2012) review were used in the current study. Two of these criteria were slightly modified to account for the multi-generational component of the data structure: "prospective measure of maltreatment" and "validated measure of maltreatment." In Thornberry et al.'s review, each generation had to be scored as meeting that criterion to receive a score of 1 . For example, if retrospective reports were used to measure maltreatment in one generation, but prospective reports were used to measure it in the other, this study would be coded as not fulfilling that criterion. This "all or none" method in Thornberry et al.'s coding approach penalizes studies that used prospective reporting in one generation and not the other. Similarly, if a study used a validated measure of maltreatment for one generation but not the other, using Thornberry et al.'s original scoring method this study would be penalized for not meeting the "validated measure of maltreatment" criterion, even though this criterion was met in at least one generation. Because of this, we elected to score each generation separately for whether maltreatment was examined prospectively versus retrospectively and whether maltreatment was assessed using a validated versus non-validated measure, resulting in a total of 13 criteria scored for each study (see Table 1).

Studies were given a score of either 0 or 1 for each criterion (see online-only Supplemental Table S.1) and were summed to give a total possible score of 13. All studies were double coded, and discrepancies were resolved through conferencing. 


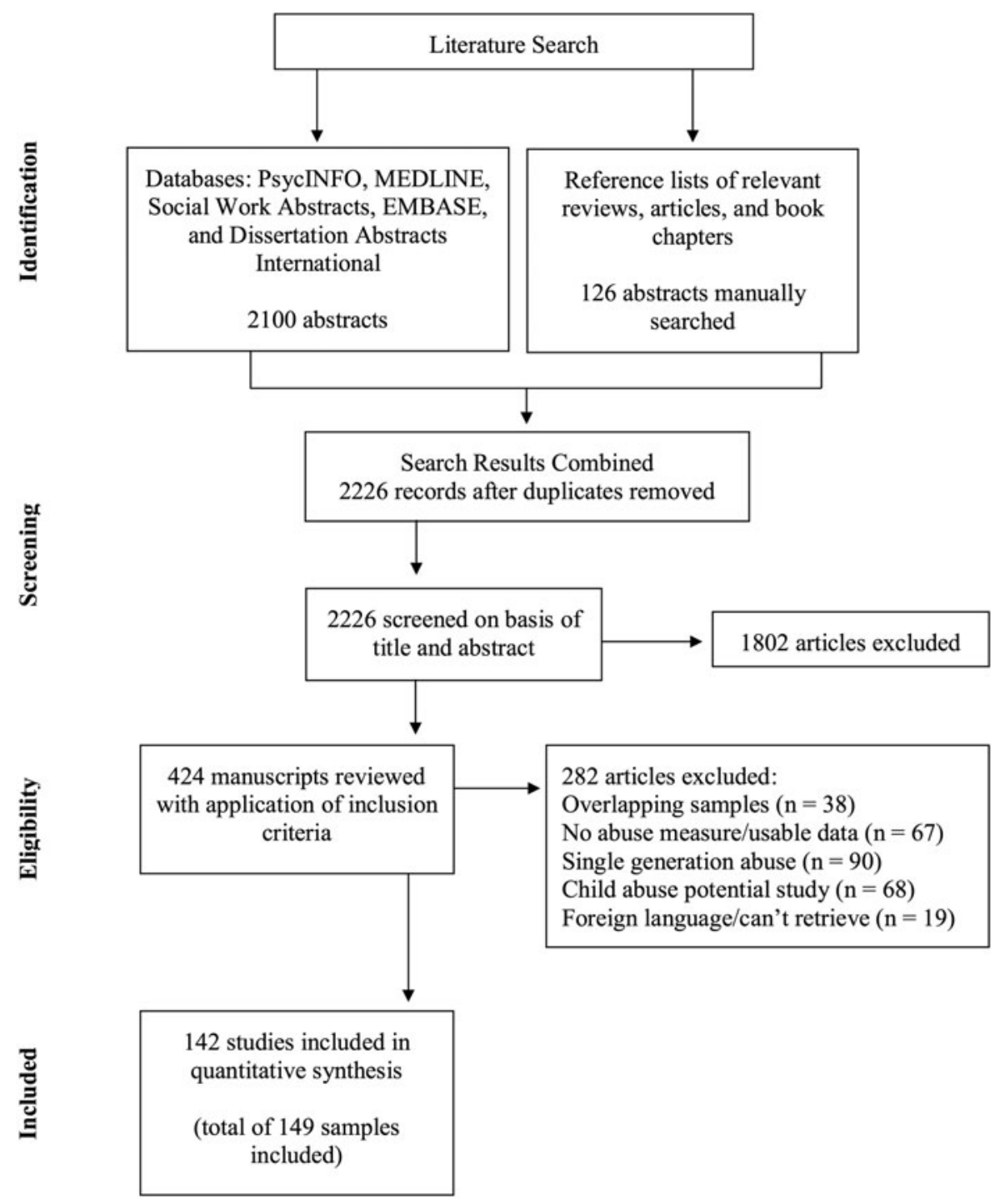

Figure 1. PRISMA flow diagram.

\section{Data extraction: Meta-analysis}

A team of three graduate research assistants, supervised by the first author, reviewed the full text of all manuscripts meeting study inclusion criteria for the purpose of extracting relevant effect sizes and for coding sample and study-level moderator variables. As described in the following sections, a structured data extraction manual was developed by study authors to ensure accuracy and reliability of the coding process. ${ }^{5}$

\section{Section 1: Background information}

This section contains preliminary information describing studies that met inclusion criteria. Relevant data included: (a) year of publication to assess for potential changes in the magnitude of effect

5. If a study had missing data but referred to another publication in which information on study methods and sample characteristics was reported, this source was reviewed to attain relevant information. sizes over time; (b) publication source (unpublished, including theses/dissertations and reports, or peer-reviewed journal articles); and (c) sample size used in analyses of intergenerational maltreatment.

\section{Section 2a: Sample characteristics}

Similar to other large-scale meta-analytic reviews (e.g., Lucas-Thompson, Goldberg, \& Prause, 2010; Madigan, Brumariu, Villani, Atkinson, \& Lyons-Ruth, 2016), for all sample characteristics, a cutoff point of $80 \%$ or higher was considered to represent the majority of the sample.

Ethnic composition. The percentage of each major ethnicity category was reported. For studies conducted in predominantly Caucasian majority settings, we inferred that the ethnicity was $100 \%$ White if no other ethnic representation was explicitly stated. From these derived values, a percentage of minority ethnicities was tallied (i.e., the total percentage 
across all minority ethnicities that was non-Caucasian). If study authors indicated that they combined two or more ethnicities together, the percentage was documented under a "mixed" ethnicity category and tallied into the final score for percentage minority. Minority status is specific to the country in which the study takes place (e.g., if the study was conducted in Japan, we did not count Asian participants as minority).

Study location. The regions in which studies were conducted were classified as follows: North America, Europe, South America, Australia and New Zealand, Asia, or Africa.

Demographic risk. The presence versus absence of the following demographic risk factors was coded: low SES, single parenthood, adolescent parenthood, and high-crime neighborhood. Subsequently, children's exposure to risk was coded dichotomously (i.e., $0=$ no risk; $1=$ one or more risks).

Child characteristics. This section included child gender and age: child gender was coded as percentage of females within the sample, and was entered as $50 \%$ female in cases where information on child gender was not provided; and child age was recorded, in months, at the time of the outcome measurement assessed.

Parental characteristics. This section included parental gender and age: parental gender was coded as percentage of the sample that was female; and maternal age was recorded, in years, at the time of the outcome measurement assessed.

\section{Section 3: Measurement characteristics}

Parental maltreatment type for $G 2$ and G3. This variable refers to the type of maltreatment that the parental generation experienced, as well as the type of maltreatment that the child generation experienced. For both G2 and G3, studies were classified into one of the following maltreatment categories: physical abuse; sexual abuse; emotional abuse; neglect; and multitype maltreatment.

G2 and G3 maltreatment measures. The type of parental and child maltreatment measure was documented as follows: questionnaire; interview; official case reports (CPS reports, hospital records, offender records, court records, etc.); and mixed methods.

Data extraction for all studies meeting inclusion criteria was conducted by a primary coder (A.L.), and double coded by at least one additional coder (C.R., J.P.). All disagreements were resolved via discussion and consensus coding. Studies that presented challenging data extraction information were reviewed with the first author (S.M.), and subsequently discussed with the remaining data extraction team.
Computation of effect sizes. A variety of statistics were used to calculate effect sizes, with the majority of studies reporting odds ratios, chi-squares, means and standard deviations, $t$ values, or correlations. For a minority of studies, effect sizes could not be precisely estimated as the association was described as "nonsignificant" without the provision of a statistical value. When effect sizes were described as "nonsignificant" $(n=7)$ across all analyses, a $p$ value of .50 was assigned (Rosenthal, 1995).

Single and multiple measures of maltreatment. As maltreatment encompasses several types, multiple effect sizes from the same study based on the same sample of children were often presented for the association between G2 maltreatment and G3 maltreatment. As we were interested in the intergenerational transmission of maltreatment generally, as well as specifically by maltreatment types, effect sizes were computed as follows (see the online-only Supplemental Figure S.1): (a) if a study provided an effect size on the association between multiple types of maltreatment ("multitype") in $\mathrm{G} 2$ and perpetration of the same multitype maltreatment in $\mathrm{G} 3$, this effect size was entered into the meta-analysis as maltreatment - > maltreatment; (b) if a study provided individual effect sizes for the association between two or more types of maltreatment (e.g., sexual, physical, emotional abuse, or neglect) for G2 and G3, but not an overall maltreatment effect size, we combined these types of maltreatment to derive a single effect size representing the broader concept of "maltreatment" and entered this effect size into the analysis on maltreatment $->$ maltreatment; (c) homotypic transmission: if a study reported on the transmission of a single type of maltreatment from G2 to G3 (e.g., physical abuse -> physical abuse), this effect size was included in the meta-analysis for that particular association; and (d) heterotypic transmission: if a study reported on the transmission of a type of crossover transmission of maltreatment from G2 to G3 (e.g., physical abuse - $>$ neglect), this effect size was only included in the meta-analysis on heterotypic transmission.

Multiple effect sizes from the same study based on different subgroups or measures. When different subgroups with different population parameters were presented, such as families from high versus low sociodemographic risk, each sample was entered separately into the meta-analysis. However, there were also instances for which results of subgroups could not be treated as independent effect sizes. Specifically, when effect sizes were presented for both mothers and fathers in G2 and G3's incidence of maltreatment, these effect sizes could not be treated as independent effect sizes as data with G3 were overlapping. In such cases, we selected the association between G2 fathers and G3 children as data on G2 fathers were underrepresented in our meta-analysis. We adopted a similar practice for studies that provided multiple measures to examine G2 or G3 maltreatment, in which we selected the most underrepresented measures of maltreatment (i.e., CPS reports). 


\section{Data analysis}

Meta-analytic strategy. Effect size computations were conducted in Comprehensive Meta-Analysis 3.0 (Borenstein et al., 2014). Effect sizes were weighted according to the inverse of their variance to ensure that more precise estimates with larger effect sizes influenced the overall effect size more heavily, and to attenuate the upwardly biased estimates of smaller sample sizes (Hedges \& Olkin, 1985). All analyses were performed using random effect models due to the variability in sampling methods and population parameters of studies included in the current meta-analysis. In addition, 95\% CIs around the mean effect size estimate were calculated. Heterogeneity of effect sizes was assessed using $Q$ statistics (Borenstein et al., 2009). Categorical moderator analyses were examined using mixed-effect models based on the $Q$ statistic for heterogeneity. Consistent with previous meta-analyses (e.g., Bakermans-Kranenburg et al., 2003), for a category to be included in the test for significant differences among levels of the moderator, at least four or more studies were required. Meta-regression analyses were used to examine continuous moderators. Finally, to assess for publication bias, the trim and fill procedure by Duval and Tweedie (2000) was used, in which an inverted funnel plot is derived to demonstrate the association between sample size and effect size. If no publication bias is present, effect sizes are symmetrically represented around the combined effect sizes. If the funnel plot is asymmetric and fewer studies with weaker effect sizes are represented on the bottom lefthand side of the mean effect size, the trim and fill procedure imputes symmetrical values to balance the funnel plot, and an adjusted mean effect size accounting for publication bias is provided.

Methodological review. The purpose of the methodological review was twofold: to assess each study for methodological quality; and to determine if methodological quality moderates effect sizes. The methodological review, described in the earlier Data Extraction section, yields a determination of whether a set of 13 predetermined criteria are met (see Table 1), as well as a total methodological quality score. To satisfy the complimentary aims of this methods review, we approach data analysis in a number of ways to determine if methodological quality had an impact on effect sizes. We examined whether (a) any of the 13 study quality criteria moderated effect sizes; (b) the total 13-point methodological quality score moderated effect sizes; (c) studies grouped according to low (scores of $\leq 5$ ), moderate (scores between 6 and 10), or high (scores of $\geq 11$ ) methodological quality moderated effect sizes; and finally, (d) consistent with the approach taken by Thornberry et al. (2012), we examined whether effect sizes varied as a function of study research design, classifying studies as follows: case reports of maltreatment in G2 and G3 (e.g., hospital reports and CPS reports); G2 self-report data on maltreatment history and G3 case reports of child maltreatment; and G2 and G3 self-report data of maltreatment. This collection of analyses was done only on data specific to the intergenerational trans- mission of maltreatment, due to insufficient studies per maltreatment type. In all other analyses on homotypic transmission, we only assessed whether the total methodological quality score is a moderator of effect sizes.

\section{Results}

\section{Sample characteristics}

Sample characteristics for each study can be found in Appendix B. Sample size ranged from 25 to 85,084 (median $N=222$ ). Overall, 94 (66.2\%) studies were conducted in North America, $26(18.3 \%)$ in Europe, 7 (4.9\%) in South America, 7 (4.9\%) in Australia and New Zealand, and $8(5.6 \%)$ in non-Western countries (i.e., Africa and Asia). A total of 35 (23.5\%) studies used some variant of the Conflict Tactics Scale (Straus, 1979), 18 (12.7\%) studies used the Childhood Trauma Questionnaire (Bernstein et al., 1994), 59 (41.5\%) studies utilized data from CPS or other official records, $30(21.1 \%)$ used other various validated measures, and 72 used measures created for the purposes of the specific study $(50.7 \%)$.

The mean age for $\mathrm{G} 2$ was 33.5 years, and on average, $72.4 \%$ were female. The mean age for G3 was 9.4 years and on average, $51.6 \%$ of children were female. A total of $39(26.2 \%)$ samples examined maltreatment of G3 perpetrated by the mother, $19(12.8 \%)$ examined maltreatment of G3 perpetrated by the father, $44(29.5 \%)$ examined maltreatment of G3 perpetrated by a nonspecified parental figure, 8 (5.4\%) examined maltreatment by any relative, and 34 $(22.8 \%)$ did not specify the identity of the perpetrator.

\section{Association between parental maltreatment history and child maltreatment}

In 80 studies, the combined effect size was significant, $d=$ 0.45 (95\% CI [0.37, 0.54]), demonstrating a moderate association between parental history of maltreatment and maltreatment in the next generation. Fifty-seven studies $(71 \%)$ had significant effect sizes, while 23 did not (29\%). There was no indication of publication bias (see Figure 2). The $Q$ statistic for heterogeneity of studies $(Q=3,339.43, p<$ .001) was significant, and moderators related to study quality, and well as substantive and study-level moderators, were conducted to explain this variability.

Methodological quality moderators. The mean score of the methodological quality review was 7.35 (range 1-12). Moderator analyses revealed that the intergenerational transmission of maltreatment did not differ based on any of the study quality criteria (see Table 2). We also examined whether the total study quality score moderated effect sizes, and findings were not significant, suggesting that the magnitude of the transmission of maltreatment did not increase or decrease based on a continuous score of methodological study quality $(b=.006 ; p=.77)$. In addition, when examined using a categorical score, the magnitude of transmission did not vary as 
Funnel Plot of Standard Error by Fisher's Z

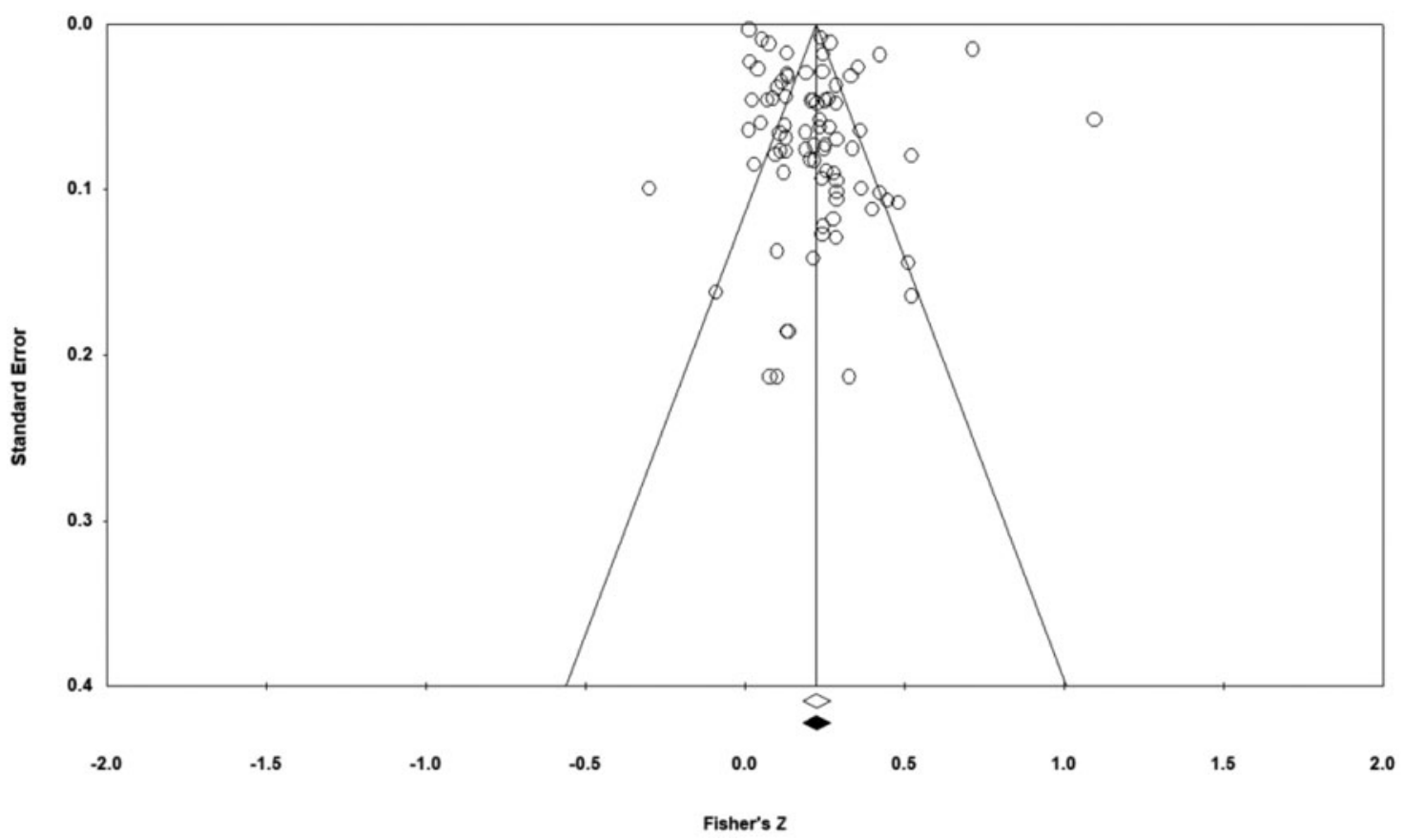

Figure 2. Funnel plot of the meta-analysis on the intergenerational transmission of maltreatment $(N=80)$. The $y$-axis on the funnel plot represents the standard error, and the $x$-axis represents the effect size. White circles indicate studies that were included in the meta-analysis. The diamonds at the bottom of the funnel plot represent the observed and adjusted effect sizes. Studies with large sample sizes appear toward the top of the graph, and smaller studies toward the bottom of the graph (due to greater sampling variation in effect size estimates in the smaller studies). Studies were symmetrically distributed around the combine effect size, and thus, no publication bias was suggested.

a function of whether studies were of low $(k=15 ; d=0.36$; $95 \%$ CI $[0.07,0.22])$, moderate $(k=53 ; d=0.50 ; 95 \%$ CI $[0.38,0.62])$, or high $(k=12 ; d=0.38 ; 95 \%$ CI $[0.26$, $0.50])$ methodological quality. Finally, effect sizes did not vary when official reports of maltreatment were used in G2 and $\mathrm{G} 3(k=9 ; d=0.31 ; 95 \% \mathrm{CI}[0.14,0.48])$, when studies had official reports of child maltreatment in G2 or G3 and self-report otherwise $(k=23 ; d=0.58 ; 95 \%$ CI [0.38, $0.78]$, or when self-report data of maltreatment was used in $\mathrm{G} 2$ and $\mathrm{G} 3(k=46 ; d=0.41 ; 95 \%$ CI $[0.32,0.50])$.

Substantive and study-level moderators. All moderator analyses are reported in Table 3. Although several moderators were tested, none emerged as significant.

\section{Homotypic continuity}

In this section, we provide meta-analytic results of maltreatment-specific type-to-type, transmission (e.g., neglect in G2 to neglect in G3).

Neglect. In 13 studies, the combined effect size was significant, $d=0.24$ (95\% CI $[0.11,0.37])$, demonstrating a link between parental history of neglect and risk of one's own child experiencing neglect. The Duval and Tweedie procedure did not indicate publication bias. The $Q$ statistic $(Q=68.06, p<$ .001) was significant, indicating heterogeneity of effect sizes, and moderator analyses were conducted to explain this varia- bility (see Table 4); however, no significant moderators emerged, including study methodological quality.

Physical abuse. In 61 studies, the combined effect size was significant, $d=0.41$ (95\% CI [0.33, 0.49]), demonstrating a link between parental history of physical abuse and risk of one's own child being physically abused. The Duval and Tweedie trim and fill procedure indicated asymmetry, suggesting that publication bias was present. Twenty-two studies were trimmed and replaced, resulting in an adjusted significant effect size of $d=0.24$ (CI [0.16, 0.33]). The $Q$ statistic $(Q=852.87, p<.001)$ was significant, indicating heterogeneity of effect sizes, and moderator analyses were conducted to explain this variability (see Table 5).

Total study quality score was a significant moderator: studies with higher methodological quality showed weaker transmission of physical abuse $(b=-.051 ; p<.05)$. Analyses also revealed that dissemination medium was a significant moderator, with unpublished studies $(k=5 ; d=0.27 ; 95 \%$ CI $[0.15,0.39])$ having weaker effect sizes compared to published studies $(k=56 ; d=0.42 ; 95 \%$ CI [0.33, 0.50]).

Emotional abuse. In 18 studies the combined effect size was significant, $d=0.57$ (95\% CI [0.43, 0.71]), demonstrating a link between parental history of emotional abuse and one's own child enduring emotional abuse. No publication bias was detected. The $Q$ statistic $(Q=42.15 ; p<.001)$ was sig- 
Table 2. Results for moderators of the study quality evaluation

\begin{tabular}{|c|c|c|c|c|c|}
\hline Categorical moderators & $k$ & $d$ & $95 \% \mathrm{CI}$ & $Q$ & $p$ value \\
\hline Representative sample & & & & 0.56 & .46 \\
\hline No & 58 & $0.43 * * *$ & {$[0.35,0.51]$} & & \\
\hline Yes & 22 & $0.50 * * *$ & {$[0.34,0.65]$} & & \\
\hline Participation/attrition & & & & 0.95 & .33 \\
\hline Unacceptable & 37 & $0.40 * * *$ & {$[0.29,0.52]$} & & \\
\hline Acceptable & 43 & $0.49 * * *$ & {$[0.37,0.61]$} & & \\
\hline Maltreated and nonmaltreated participants included & & & & 0.02 & .90 \\
\hline No & 7 & $0.47 * * *$ & {$[0.20,0.74]$} & & \\
\hline Yes & 73 & $0.45 * * *$ & {$[0.36,0.54]$} & & \\
\hline Confirmation of nonmaltreatment status & & & & 1.50 & .22 \\
\hline No & 34 & $0.51 * * *$ & {$[0.36,0.62]$} & & \\
\hline Yes & 46 & $0.41 * * *$ & {$[0.33,0.48]$} & & \\
\hline Use of controls in analyses & & & & 0.46 & .50 \\
\hline No & 24 & $0.41 * * *$ & {$[0.31,0.51]$} & & \\
\hline Yes & 56 & $0.46 * * *$ & {$[0.36,0.56]$} & & \\
\hline G2 prospective data & & & & 0.86 & .36 \\
\hline No & 79 & $0.45 * * *$ & {$[0.37,0.54]$} & & \\
\hline Yes & 1 & $0.39 * * *$ & {$[0.27,0.50]$} & & \\
\hline G3 prospective data & & & & 0.05 & .82 \\
\hline No & 59 & $0.44 * * *$ & {$[0.36,0.53]$} & & \\
\hline Yes & 21 & $0.47 * * *$ & {$[0.29,0.64]$} & & \\
\hline Single/multiple informants & & & & 0.46 & .50 \\
\hline Single & 29 & $0.42 * * *$ & {$[0.31,0.53]$} & & \\
\hline Multiple & 51 & $0.47 * *$ & {$[0.37,0.58]$} & & \\
\hline Same exposure period for maltreated and nonmaltreated groups & & & & 0.85 & .36 \\
\hline No $T$ r the & 5 & $0.58 * * *$ & {$[0.30,0.87]$} & & \\
\hline Yes & 75 & $0.44 * * *$ & {$[0.36,0.53]$} & & \\
\hline Follow-up exposure & & & & 0.33 & .57 \\
\hline Low $(\mathrm{G} 3<5$ years of age $)$ & 27 & $0.41 * * *$ & {$[0.20,0.61]$} & & \\
\hline Adequate $(\mathrm{G} 3>5$ years of age $)$ & 53 & $0.47 * * *$ & {$[0.39,0.55]$} & & \\
\hline G2 valid instrument & & & & 0.52 & .47 \\
\hline No & 27 & $0.41 * * *$ & {$[0.29,0.54]$} & & \\
\hline Yes & 53 & $0.47 * * *$ & {$[0.37,0.57]$} & & \\
\hline G3 valid instrument & & & & 1.56 & .21 \\
\hline No & 16 & $0.37 * * *$ & {$[0.22,0.51]$} & & \\
\hline Yes & 64 & $0.48 * * *$ & {$[0.38,0.57]$} & & \\
\hline Maltreatment defined & & & & 2.43 & .12 \\
\hline No & 45 & $0.51 * * *$ & {$[0.36,0.66]$} & & \\
\hline Yes & 35 & $0.37 * * *$ & {$[0.28,0.46]$} & & \\
\hline Study Qquality $^{a}$ & & & & 2.66 & .27 \\
\hline Low $($ score of $\leq 5)$ & 15 & $0.36 * * *$ & {$[0.07,0.22]$} & & \\
\hline Moderate (score between 6 and 9) & 53 & $0.50 * * *$ & {$[0.38,0.62]$} & & \\
\hline High $($ score $>10)$ & 12 & $0.38 * * *$ & {$[0.26,0.50]$} & & \\
\hline Research design & & & & 4.00 & .14 \\
\hline Case reports in both G2 and G3 & 9 & $0.31 * * *$ & {$[0.14,0.48]$} & & \\
\hline Case reports in either $\mathrm{G} 2$ or $\mathrm{G} 3$ & 23 & $0.58 * * *$ & {$[0.38,0.78]$} & & \\
\hline Self-report in both G2 and G3 & 46 & $0.41 * * *$ & {$[0.32,0.50]$} & & \\
\hline Continuous moderator & $k$ & $b$ & $\begin{array}{c}95 \% \text { CI } \\
\text { Lower Upper }\end{array}$ & $Z$ value & $p$ value \\
\hline Study quality score & 80 & .007 & -.037 .050 & 0.31 & .76 \\
\hline
\end{tabular}

${ }^{a}$ Minimum and maximum scores on the study quality index are 0 and 13 , respectively. ${ }^{* *} p<.01 . * * p<.001$.

nificant, indicating heterogeneity of effect sizes, and moderator analyses were conducted to explain this variability (see Table 6). Several moderator variables were examined, but none emerged as significant, including study methodological quality.
Sexual abuse. In 18 studies, the combined effect size was significant, $d=0.39$ (95\% CI [0.24, 0.55]), demonstrating a link between parental history of sexual abuse and risk of one's child experiencing sexual abuse. Publication bias was indicated. Using the trim and fill procedure, 5 studies were re- 
Table 3. Results of categorical and continuous moderators for the associations between parental history of maltreatment and child maltreatment

\begin{tabular}{|c|c|c|c|c|c|}
\hline Categorical moderators & $k$ & $d$ & $95 \% \mathrm{CI}$ & Q & $p$ \\
\hline G2 measure & & & & 3.16 & .21 \\
\hline Case reports & 9 & $0.31 * * *$ & {$[0.14,0.48]$} & & \\
\hline Interview & 16 & $0.53 * * *$ & {$[0.34,0.73]$} & & \\
\hline Questionnaire & 52 & $0.46 * * *$ & {$[0.34,0.57]$} & & \\
\hline G3 measure & & & & 3.06 & .38 \\
\hline Case reports & 28 & $0.48 * * *$ & {$[0.32,0.64]$} & & \\
\hline Interview & 4 & 0.32 & {$[-0.02,0.66]$} & & \\
\hline Mixed methods & 6 & $0.51 * * *$ & {$[0.44,0.57]$} & & \\
\hline Questionnaire & 40 & $0.41 * * *$ & {$[0.31,0.52]$} & & \\
\hline Demographic risk & & & & 2.85 & .10 \\
\hline No & 54 & $0.48 * * *$ & {$[0.37,0.58]$} & & \\
\hline Yes & 26 & $0.36 * * *$ & {$[0.28,0.45]$} & & \\
\hline Dissemination medium & & & & 3.34 & .07 \\
\hline Unpublished & 9 & $0.60 * * *$ & {$[0.44,0.76]$} & & \\
\hline Publication & 71 & $0.43 * * *$ & {$[0.34,0.52]$} & & \\
\hline Country of origin & & & & 0.08 & .78 \\
\hline Europe & 18 & $0.49 * * *$ & {$[0.23,0.74]$} & & \\
\hline North America & 53 & $0.45 * * *$ & {$[0.37,0.54]$} & & \\
\hline Continuous moderators & $k$ & $b$ & $\begin{array}{c}95 \% \text { CI } \\
\text { Lower Upper }\end{array}$ & $Z$ value & $p$ \\
\hline Child age & 72 & .000 & -.001 .001 & 0.36 & .71 \\
\hline Mother age & 59 & .002 & -.009 .012 & 0.32 & .75 \\
\hline Child gender ( $\%$ female) & 80 & .001 & -.005 .007 & 0.34 & .74 \\
\hline Parent gender ( $\%$ female $)$ & 80 & .000 & -.002 .002 & 0.03 & .98 \\
\hline Ethnicity (\% minority) & 70 & -.002 & -.004 .000 & -1.72 & .09 \\
\hline Year of publication & 80 & -.006 & -.013 .002 & -1.57 & .11 \\
\hline Sample size & 80 & .000 & .000 .000 & 0.40 & .78 \\
\hline
\end{tabular}

$* * * p<.001$.

Table 4. Results of categorical and continuous moderators for the associations between parental history of neglect and child neglect

\begin{tabular}{|c|c|c|c|c|c|}
\hline Categorical moderators & $k^{a}$ & $d$ & $95 \% \mathrm{CI}$ & $Q$ & $p$ \\
\hline \multicolumn{4}{|l|}{ G2 measure } & \multirow[t]{3}{*}{0.26} & \multirow[t]{3}{*}{.61} \\
\hline Case reports & 4 & $0.32 * * *$ & {$[0.22,0.41]$} & & \\
\hline Questionnaire & 8 & $0.26 * *$ & {$[0.08,0.45]$} & & \\
\hline \multicolumn{4}{|l|}{ G3 measure } & \multirow[t]{3}{*}{1.89} & \multirow[t]{3}{*}{.17} \\
\hline Case reports & 5 & $0.28 * *$ & {$[0.20,0.35]$} & & \\
\hline Questionnaire & 5 & 0.15 & {$[-0.02,0.32]$} & & \\
\hline \multicolumn{6}{|l|}{ Demographic risk } \\
\hline No & & $0.28 * * *$ & {$[0.09,0.48]$} & \multirow[t]{2}{*}{0.59} & \multirow[t]{2}{*}{.44} \\
\hline Yes & 85 & 0.20 & {$[0.11,0.29]$} & & \\
\hline Continuous moderator & $k$ & $b$ & $\begin{array}{c}95 \% \text { CI } \\
\text { Lower Upper }\end{array}$ & $Z$ value & $p$ \\
\hline Child age & 13 & .000 & -.001 .001 & -0.20 & .84 \\
\hline Mother age & 8 & -.008 & -.024 .008 & -0.96 & .34 \\
\hline Child gender ( $\%$ female) & 13 & .006 & -.034 .050 & 0.26 & .80 \\
\hline Parent gender ( $\%$ female $)$ & 13 & -.002 & -.005 .002 & -0.81 & .42 \\
\hline Ethnicity (\% minority) & 12 & .002 & -.002 .006 & 1.09 & .29 \\
\hline Year of publication & 13 & -.003 & -.014 .020 & 0.32 & .75 \\
\hline Study sample size & 13 & .000 & .000 .000 & 1.85 & .07 \\
\hline Study quality & 13 & -.001 & -.071 .069 & -0.02 & .98 \\
\hline
\end{tabular}

${ }^{a}$ Only moderators that had a sufficient number of studies $(\geq 4)$ at each level of the moderator variable are reported. $* * p<.01$. $* * * p<.001$. 
Table 5. Results of categorical and continuous moderators for the associations between parental history of physical abuse and child physical abuse

\begin{tabular}{|c|c|c|c|c|c|}
\hline Categorical moderators & $k^{a}$ & $d$ & $95 \% \mathrm{CI}$ & $Q$ & $p$ \\
\hline G2 measure & & & & 2.94 & .09 \\
\hline Interview & 14 & $0.31 * * *$ & {$[0.18,0.44]$} & & \\
\hline Questionnaire & 46 & $0.45^{* * *}$ & {$[0.35,0.54]$} & & \\
\hline G3 measure & & & & 3.64 & .16 \\
\hline Case reports & 9 & $0.26 * * *$ & {$[0.12,0.40]$} & & \\
\hline Interview & 8 & $0.35 * * *$ & {$[0.15,0.54]$} & & \\
\hline Questionnaire & 40 & $0.42 * * *$ & {$[0.33,0.51]$} & & \\
\hline Demographic risk & & & & 1.33 & .25 \\
\hline No & 47 & $0.42 * * *$ & {$[0.33,0.52]$} & & \\
\hline Yes & 14 & $0.34 * * *$ & {$[0.23,0.45]$} & & \\
\hline Dissemination medium & & & & 3.91 & .05 \\
\hline Unpublished & 5 & $0.27 * * *$ & {$[0.15,0.39]$} & & \\
\hline Publication & 56 & $0.42 * * *$ & {$[0.33,0.50]$} & & \\
\hline Country of origin & & & & 2.50 & .48 \\
\hline Australia & 5 & $0.42 * *$ & {$[0.19,0.66]$} & & \\
\hline Asia & 5 & $0.40 * *$ & {$[0.17,0.63]$} & & \\
\hline Europe & 16 & $0.52 * * *$ & {$[0.35,0.70]$} & & \\
\hline North America & 31 & $0.36^{* *}$ & {$[0.27,0.46]$} & & \\
\hline Continuous moderators & $k$ & $b$ & $\begin{array}{c}95 \% \text { CI } \\
\text { Lower Upper }\end{array}$ & Zvalue & $p$ \\
\hline Child age & 48 & .000 & -.001 .001 & -0.62 & .54 \\
\hline Mother age & 43 & -.006 & -.018 .006 & -0.98 & .32 \\
\hline Child gender ( $\%$ female) & 61 & -.002 & -.008 .005 & -0.50 & .62 \\
\hline Parent gender ( $\%$ female) & 61 & -.001 & -.002 .001 & -0.69 & .49 \\
\hline Ethnicity (\% minority) & 54 & -.002 & -.004 .001 & -1.31 & .19 \\
\hline Year of publication & 61 & -.004 & -.012 .005 & -0.87 & .38 \\
\hline Study sample size & 61 & .000 & .000 .000 & -0.61 & .54 \\
\hline Study quality & 61 & -.051 & -.094 .009 & -2.39 & .02 \\
\hline
\end{tabular}

${ }^{a}$ Only moderators that had a sufficient number of studies $(\geq 4)$ at each level of the moderator variable are reported. $* * p<.01$. $* * * p<.001$.

quired to create symmetry in the funnel plot, resulting in an adjusted observed effect size of $d=0.22$ (CI [0.05, 0.39]). The $Q$ statistic $(Q=108.63, p<.0001)$ was significant, indicating heterogeneity of effect sizes, and moderator analyses were conducted to explain this variability (see Table 7).

Effect size varied as a function of the type of measure used to assess child sexual abuse. Effect sizes were stronger in studies using official records $(k=7 ; d=0.59 ; 95 \% \mathrm{CI}$ $[0.33,0.85])$ compared to studies using questionnaire measures $(k=6 ; d=0.04 ; 95 \%$ CI $[-0.11,0.20)$. In addition, effect sizes strengthened as the percentage of females in samples increased $(b=.010 ; p<.01)$, and as the percentage of mothers versus fathers in samples increased $(b=.005 ; p<$ .02). Finally, effect sizes were stronger in studies from North America $(k=11 ; d=0.17 ; 95 \%$ CI $[0.25,0.57])$ versus Europe $(k=5 ; d=0.10 ; 95 \%$ CI $[-0.04,0.24])$. Study methodological quality did not moderate effect sizes.

\section{Heterotypic continuity}

In this section, we examine if a parent's experience of certain types of maltreatment create a propensity for their own child to be a victim of other types of maltreating behavior (e.g., physical abuse in G2 to emotional abuse in G3).

Parental maltreatment type: Neglect. The effect size for parental neglect to child physical abuse $(k=15)$ was significant, $d=0.20$ (95\% CI [0.06, 0.33]), suggesting a crossover association in which parental history of neglect is linked to a greater chance that one's own child is physically abused. Significant crossover was also observed for parental neglect to child sexual abuse $(k=6 ; d=0.25 ; 95 \%$ CI $[0.04,0.46])$. However, the effect size for the crossover transmission from parental history of neglect to child emotional abuse was not significant $(k=9 ; d=0.15 ; 95 \%$ CI $[-0.07,0.37])$.

Parental maltreatment type: Physical abuse. The effect size for parental physical abuse to child neglect $(k=13)$ was significant, $d=0.30$ (95\% CI [0.20, 0.41]). Effect sizes for the crossover transmission of parental history of physical abuse to child emotional abuse $(k=17 ; d=0.40 ; 95 \%$ CI [0.32, 0.47]) and sexual abuse $(k=9 ; d=0.30 ; 95 \%$ CI $[0.03,0.56])$ were also significant. Thus, parental history of physical abuse is associated with all types of child maltreatment outcomes. 
Table 6. Results of categorical and continuous moderators for the associations between parental history of emotional abuse and child emotional abuse

\begin{tabular}{lccccc}
\hline \hline Categorical moderators & $k^{a}$ & $d$ & $95 \%$ CI & $Q$ & $p$ \\
\hline $\begin{array}{l}\text { Dissemination medium } \\
\quad \text { Unpublished }\end{array}$ & 5 & $0.64^{* *}$ & {$[0.20,1.08]$} & 0.10 & .75 \\
$\quad \begin{array}{l}\text { Publication } \\
\text { Country of origin }\end{array}$ & 13 & $0.56^{* * *}$ & {$[0.42,0.71]$} & & \\
$\quad$ Europe & & & & \\
$\quad$ North America & 8 & $0.46^{* * *}$ & {$[0.21,0.71]$} & & \\
& 6 & $0.71^{* * *}$ & {$[0.39,1.02]$} & & \\
& & & & & \\
Continuous moderators & $k$ & $b$ & Lower Upper & Zvalue & \\
\hline Child age & 16 & -.001 & -.002 .000 & -1.30 & .20 \\
Mother age & 9 & .002 & -.030 .033 & 0.11 & .92 \\
Child gender (\% female) & 17 & -.006 & -.042 .054 & -0.24 & .81 \\
Parent gender (\% female) & 18 & .001 & -.003 .005 & 0.54 & .59 \\
Ethnicity (\% minority) & 15 & .005 & -.005 .014 & 0.94 & .34 \\
Year of publication & 18 & -.006 & -.022 .010 & -0.71 & .48 \\
Study sample size & 18 & .000 & .000 .000 & 0.44 & .66 \\
Study quality score & 18 & -.031 & -.138 .076 & -0.57 & .57 \\
\hline \hline
\end{tabular}

${ }^{a}$ Only moderators that had a sufficient number of studies $(\geq 4)$ at each level of the moderator variable are reported. $* * p<.01$. $* * * p<.001$.

Parental maltreatment type: Emotional abuse. The effect sizes for parental emotional abuse to child physical $(k=13$; $d=0.30 ; 95 \%$ CI $[0.17,0.43])$ and sexual abuse $(k=7$; $d=0.34 ; 95 \%$ CI $[0.10,0.57])$ were significant. However, effect sizes for the crossover transmission of parental history of emotional abuse to child neglect was not significant $(k=7$; $d=0.17 ; 95 \%$ CI $[-0.03,0.37])$.

Parental maltreatment type: Sexual abuse. The effect sizes for parental history of sexual abuse to child neglect $(k=$

Table 7. Results of categorical and continuous moderators for the associations between parental history of sexual abuse and child sexual abuse

\begin{tabular}{|c|c|c|c|c|c|}
\hline Categorical moderators & $k^{a}$ & $d$ & $95 \% \mathrm{CI}$ & $Q$ & $p$ \\
\hline G2 measure & & & & 0.64 & .42 \\
\hline Interview & 4 & $0.47 * *$ & {$[0.18,0.77]$} & & \\
\hline Questionnaire & 11 & $0.32 * *$ & {$[0.10,0.55]$} & & \\
\hline G3 measure & & & & 12.46 & .001 \\
\hline Case reports & 7 & $0.59 * * *$ & {$[0.33,0.85]$} & & \\
\hline Questionnaire & 6 & 0.04 & {$[-0.11,0.20]$} & & \\
\hline Country of origin & & & & 5.95 & .02 \\
\hline Europe & 5 & 0.10 & {$[-0.04,0.24]$} & & \\
\hline North America & 8 & $0.46^{* * *}$ & {$[0.21,0.70]$} & & \\
\hline Continuous moderators & $k$ & $b$ & $\begin{array}{c}95 \% \text { CI } \\
\text { Lower Upper }\end{array}$ & $Z$ value & $p$ \\
\hline Child age & 15 & -.002 & $-.003-.001$ & -1.84 & .07 \\
\hline Mother age & 7 & -.001 & -.023 .022 & -0.06 & .96 \\
\hline Child gender ( $\%$ female $)$ & 18 & .010 & .003 .016 & 3.00 & .01 \\
\hline Parent gender ( $\%$ female) & 18 & .005 & .001 .010 & 2.39 & .02 \\
\hline Ethnicity (\% minority) & 15 & .007 & -.002 .015 & 1.48 & .14 \\
\hline Year of publication & 18 & -.002 & -.022 .018 & -0.18 & .86 \\
\hline Study sample size & 18 & .000 & .000 .000 & -0.92 & .36 \\
\hline Study quality score & 18 & .021 & -.065 .11 & 0.47 & .64 \\
\hline
\end{tabular}

${ }^{a}$ Only moderators that had a sufficient number of studies $(\geq 4)$ at each level of the moderator variable are reported. $* * p<.01$. $* * * p<.001$. 


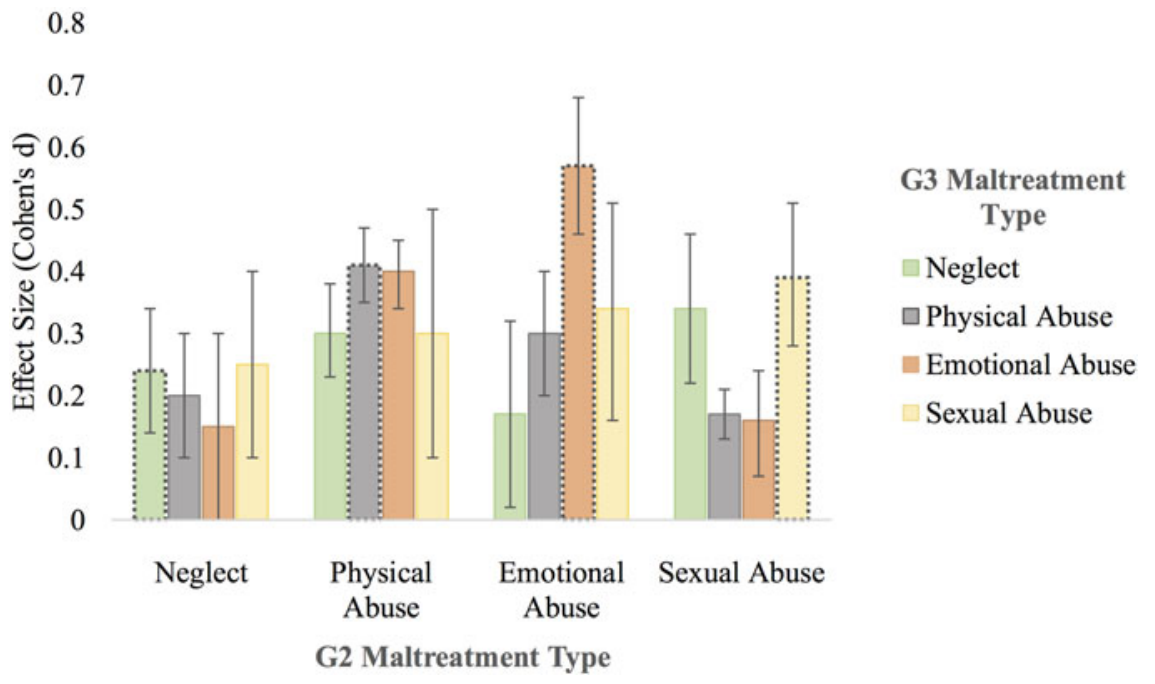

Figure 3. Comparison of homotypic and heterotypic transmission effects from G2 to G3 with $85 \%$ confidence intervals. Homotypic continuity for each maltreatment is indicated by a dotted line.

$11 ; d=0.34 ; 95 \%$ CI $[0.17,0.51])$, child physical abuse $(k=$ $21 ; d=0.17 ; 95 \% \mathrm{CI}[0.11,0.23])$, and emotional abuse $(k=$ $11 ; d=0.16 ; 95 \%$ CI $[0.04,0.27])$ were significant. Thus, parental history of sexual abuse is associated with all types of child maltreatment outcomes.

\section{Comparing homotypic and heterotypic intergenerational maltreatment}

Figure 3 provides a graphical illustration of all effect sizes for heterotypic and homotypic intergenerational transmission, for each type of maltreatment (e.g., the effect size for G2 to G3 neglect is compared to the effect sizes for G2 neglect to G3 physical, emotional, and sexual abuse). In addition to mean estimates of transmission, $85 \%$ CIs around the mean are displayed. When the $85 \%$ CIs overlap, we assume no statistically significant difference between groups (Julious, 2004). For neglect and physical abuse, all CIs overlap, suggesting no differentiation in the magnitude of associations between homotypic and heterotypic transmission for these maltreatment types. These findings suggest that $\mathrm{G} 2$ experiencing neglect or physical abuse places G3 at risk of experiencing several types of maltreatment. For emotional abuse, no effect size differences were observed for homotypic transmission compared to heterotypic transmission from G2 emotional abuse to G3 sexual abuse. However, the effect size for the homotypic transmission of emotional abuse was stronger than heterotypic transmission from G2 emotional abuse to G3 neglect, and G2 emotional abuse to G2 physical abuse. For sexual abuse, the effect size for homotypic transmission did not differ from the heterotypic transmission from G2 sexual abuse to G3 neglect; however, homotypic transmission of sexual abuse was stronger than heterotypic transmission from G2 sexual abuse to G3 physical abuse and G3 emotional abuse.

\section{Discussion}

Child maltreatment represents a major global public health problem. Attaining a clear understanding of which preexisting factors may place children at risk of maltreatment is of critical importance for prevention. Elucidating the extent to which a history of maltreatment in one generation raises the risk of maltreatment in the next is vitally important for helping practitioners develop and implement targeted strategies to reduce rates of child maltreatment (Kim, Capaldi, Pears, Kerr, $\&$ Owen, 2009). Moreover, robust evidence from multiple high-quality studies can provide crucial evidence regarding the cycle of maltreatment hypothesis, which has been debated for decades. The results of our study reveal that, compared to parents without maltreatment histories, parents who experienced childhood maltreatment are significantly more likely to have children who are also victims of maltreatment. We also found support for heterotypic and homotypic transmission of maltreatment types. For the most part, all effect sizes were small to moderate in magnitude (Cohen, 1992). The intergenerational transmission of physical abuse was moderated by study quality, but otherwise, there was little indication that study methodological quality moderated effect sizes. Perhaps most important, even in the highest quality studies on the intergenerational transmission of maltreatment, effect sizes were statistically significant.

\section{Methodological quality and the intergenerational transmission of maltreatment}

It has been well documented that child maltreatment research is rife with methodological complexities (Berlin, Appleyard, \& Dodge, 2011), and a number of authors have suggested that rigorous studies produce much smaller effect sizes, which may limit the importance of past maltreatment as a prognostic 
indicator of offspring risk. In order to comprehensively examine whether variation in methodological quality resulted in a weakening of the intergenerational transmission of maltreatment, we employed several empirical approaches, derived from traditional meta-analytic methods (e.g., assessment of categorical and continuous study quality indicators), as well as from previous narrative reviews that stratified studies based on research designs and assessed the strength of the association of intergenerational transmission via each study's statistical significance (e.g., Thornbery et al., 2012). Results of the current meta-analysis revealed that, in general, the strength of the intergenerational transmission of maltreatment does not vary as a function of study methodological quality. Thus, this meta-analytic synthesis does not support the claim that the "cycle of maltreatment" hypothesis becomes less certain in studies with higher methodological rigor (e.g., Kaufman \& Zigler, 1987; Thornberry et al., 2012). There was one exception to this finding, however; study quality moderated the intergenerational transmission of physical abuse, with effect sizes weakening as study quality increased.

For decades, there has been a consistent plea in the literature to utilize strong research designs to derive firm conclusions regarding the magnitude of cross-generational associations. It is possible that, more recently, there has been a domain-wide improvement in methodology. For example, in Thornberry et al.'s, (2012) review, the authors identified only one study that met the high standard criterion of assessing intergenerational maltreatment via child protective service records in both the parent and the child, whereas the current meta-analysis found nine studies that met this criterion, and eight of these nine studies (89\%) demonstrated significant intergenerational transmission of maltreatment.

Of note, in our review, no study scored perfectly on our methodological quality indicators. Key requirements for rigorous research designs include, at a minimum, obtaining reports of maltreatment from multiple sources or measures to enhance reliability of findings and to avoid cross-sectional retrospective recall of G2 and G3 maltreatment, observing a long follow-up period of G3 maltreatment that ideally covers a considerable portion of the childhood years, using adequate controls in all statistical analyses, a gold standard practice in developmental science more broadly, and recruitment of participants in community samples to avoid selection bias. The most prudent methodological approach is to use multiple measures to assess maltreatment within any given generation, as well as across generations (Berlin et al., 2011; Widom \& Wilson, 2015).

It is important to keep in mind that there is no single measure or method that can consistently and completely identify all maltreated and/or nonmaltreated individuals. Some degree of error or "noise" is common in all scientific methods. Thus, estimates of maltreatment, and its correlation across generations, may continue to be over- and/or underestimated, at least to some extent, due to the prodigious measurement challenges inherent to research in this field. This may especially be the case for the intergenerational transmission of physical abuse, where methodological quality appears to be particularly relevant for understanding the magnitude of associations. This was demonstrated by the attenuation of effect sizes in higher quality studies, as well as in studies that were unpublished versus published. Thus, results from the current study are in line with conclusions from Ertem et al. (2000), who suggest that further investigation into the methodological complexities of the intergenerational transmission of physical abuse in particular are needed in order to derive concrete conclusions on the purported generational continuity of physical abuse. As there is no gold standard method for the identification of any type of maltreatment, Widom et al. (2015) argue that future research should use a multimeasure or multi-informant approach to assess for maltreatment experiences, and likely physical abuse experiences in particular. Moreover, researchers should be aware that there are serious limitations to cross-sectional snapshots of parental and child maltreatment histories. Many studies designs start with a sample of parents and work backward to inquire about their childhood maltreatment histories. As a result, these designs do not include individuals who were maltreated as children but did not go on to become parents, which may influence effect size estimates (Widom \& Wilson, 2015). These should be important considerations in future research.

\section{Other moderators of the intergenerational transmission of maltreatment}

Several important moderators were identified in the current study for the intergenerational transmission of sexual abuse in particular. Transmission of sexual abuse was found to be highest when G3 measures of abuse were assessed via case reports (e.g., CPS reports; $d=0.59$ ) versus questionnaires $(d=0.11)$. This finding potentially suggests a degree of the caregiver underreporting the child's history of sexual abuse in questionnaire measures. This may occur because the caregiver is unaware that sexual abuse is occurring or has transpired. Moreover, physical diagnostic evidence of child sexual abuse occurs in less than $5 \%$ of youth who receive a medical exam for suspicion of child sexual abuse (Smith, Raman, Madigan, Waldman, \& Shouldice, 2018), and typically there are no witnesses to report the abuse. Thus, the caregiver's report and/or awareness of their child's sexual abuse history are typically contingent on the child disclosing abuse, which many children are reluctant to do (see Azzopardi, Eirich, Rash, MacDonald, \& Madigan, in press, for a meta-analysis.).

Child and parent gender explained between-study heterogeneity in the generational continuity of child sexual abuse, with intergenerational transmission being stronger in studies with more female children and female caregivers. These findings are not altogether surprising given the established asymmetry in child sexual abuse across genders, with the worldwide prevalence of child sexual abuse in girls being over twice that of boys (18\% vs. $7.6 \%$; Stoltenborgh et al., 2011). There is also research suggesting that males are 
more reluctant to disclose sexual abuse due to gender-based socialization of men as aggressors versus victims, a lack of awareness that abuse has occurred, as well as concerns of being stigmatized and shamed (Coxell, King, Mezey, \& Gordon, 1999; Lippert, Cross, Jones, \& Walsh, 2009; Romano \& De Luca, 2001; see Azzopardi, Eirich, Rash, MacDonald, \& Madigan, in press, for a meta-analysis.).

\section{Heterotypic versus homotypic continuity}

In large part, both homotypic and heterotypic intergenerational transmission of maltreatment were observed and were small to moderate in magnitude. The findings of homotypic transmission suggest that a parent who has experienced a particular type of maltreatment, for example, physical abuse, is more likely to have a child who also experiences this type of abuse. The exception to the heterotypic finding was for the intergenerational transmission of neglect. Across the studies we reviewed, parents with a history of experiencing neglect (G2) were more likely to have children (G3) who also experienced neglect and physical abuse, but not emotional or sexual abuse. There was also no heterotypic transmission from G2 emotional abuse to G3 neglect. One explanation may lie in the definitional heterogeneity of neglect and emotional abuse, which can be difficult concepts to operationalize due to the wide range of behaviors covered by the definition, cultural factors involved, and variability in how the construct is measured (see Mennen, Kim, Sang, \& Trickett, 2010). For example, neglect has many different manifestations, including medical neglect, emotional neglect, physical neglect, and relates to acts of omission of care rather than acts of commission of inadequate care. In addition, these forms of maltreatment, known as "hidden hurts," may have fewer immediate tangible impacts compared to physical and sexual abuse, and as a result, they may be more likely to be underreported, which could influence the magnitude of intergenerational transmission.

In regard to heterotypic transmission, in general findings suggest that when a parent experiences a particular type of maltreatment, again with physical abuse as an example, his/ her child is more likely to experience other forms of maltreatment as well, such as emotional abuse, sexual abuse, or neglect. Heterotypic transmission is consistent with research demonstrating that victims of child maltreatment are often exposed to multiple, co-occurring types of child maltreatment. For example, in a Canadian prevalence study, children exposed to multiple forms of maltreatment represented approximately $20 \%$ of all substantiated cases (Trocmé, Knoke, \& Blackstock, 2004). In a similar prevalence study from the Netherlands, approximately $40 \%$ of all substantiated cases of maltreatment reported involved more than one type of maltreatment (Euser et al., 2013).

The homotypic and heterotypic transmission of sexual abuse merits particular attention. The "transmission" of sexual abuse is not analogous to the other transmission types, in that the parent who experiences sexual abuse is rarely the perpetrator of sexual abuse toward his or her own child. It is a common misperception is that victims of child sexual abuse will progress from victims to victimizers. While the victim-to-victimizer cycle of sexual abuse has been shown to occur to some extent in men, it is a rarity in women (Glasser et al., 2001). What then, perpetuates the intergenerational transmission of sexual abuse? Undoubtedly, there are several factors at play. One postulation is that the intergenerational transmission of sexual abuse is a result of a parent failing to provide adequate protection and/or supervision to the child. For example, Fleming, Mullen, and Bammer (1997) found that children whose mothers had alcohol problems were at an increased risk of experiencing sexual assault, due, at least in part, to lack of supervision while intoxicated. Having a parent with a mental illness has also been associated with an increased risk for experiencing sexual abuse (Felitti et al., 1998). Finkelhor, Hotaling, Lewis, and Smith (1990) have also suggested that children who receive inadequate care may seek out positive attention and affection from others, which creates vulnerability to victimization. Thus, a parent's inability to provide a supportive and protective environment, as well as his or her failure to recognize and appropriately assess cues of danger or threat, may perpetuate the cycle of sexual abuse.

\section{Continuity and discontinuity of intergenerational maltreatment}

As noted by Kaufman and Zigler (1987), there are many negative consequences to being a victim of childhood maltreatment, and one subsumed consequence is that victims of child maltreatment will themselves become perpetrators of child maltreatment. However, it would be imprudent to assume that such individuals are unable to "break the cycle" of maltreatment. In their review Kaufman and Zigler (1987) estimated that the majority $(70 \%)$ of those maltreated as children did not become child perpetrators of maltreatment. Moreover, effect sizes for intergenerational transmission in the current series of meta-analyses were, albeit significant, small to moderate. Thus, being maltreated as a child puts an individual at risk of perpetuating maltreatment, but this association is far from deterministic.

Instances of "lawful discontinuity" are equally important for understanding family processes and dynamics, and development more broadly (Belsky, 1993; Berzenski et al., 2014). A dual focus on continuity and discontinuity can provide insight into factors that persist or desist the likelihood of intergenerational transmission, which is key to understanding the mechanisms of transmission. For example, there is meta-analytic evidence that the presence of safe, stable, nurturing relationships is an important moderator in the transmission of maltreatment (Schofield, Lee, \& Merrick, 2013). In general, maltreated individuals who report more emotional intimacy, relationship satisfaction, support, and warmth in relationships with parents, siblings, and intimate partners, are less likely to maltreat their own children compared to maltreated indi- 
viduals who did not report having these safe, stable, nurturing relationships (Schofield et al., 2013). However, the ability to engage in these types of relationships is most likely not distributed randomly and may be influenced by the type and severity of the maltreatment. Future research could shed light on the factors that are independent of the experience of maltreatment and play a pivotal role in preventing intergenerational transmission.

One viable approach to further understanding who effectively breaks the cycle of maltreatment is through experimental manipulation. For example, randomized controlled (micro)trials could be implemented in which single possible factors that could break the cycle of maltreatment are systematically manipulated (e.g., by providing couple's therapy or therapy focused on increased emotion understanding) to test whether these factors can decrease the likelihood of passing maltreatment on to the next generation. Future research on continuity and discontinuity may also benefit from a broader approach that includes maintainers (continuity), cycle breakers (discontinuity), and activators (no abuse in G2 $\rightarrow$ abuse in G3) to further understand, predict, and identify targets for prevention (see St.Laurent, Dubois-Comtois, Milot, \& Cantinotti, 2019).

\section{Clinical implications}

Several clinical implications for the diverse array of professionals working with families emerge from this meta-analysis, both at the assessment and the intervention levels. Considering the demonstrated transmission effects, this meta-analysis suggests that assessments should include asking parents about their own histories of maltreatment to provide a clue into the potential risks posed to their children. Again, the use of multiple sources of information is recommended to adequately assess past histories of maltreatment. It is important to reiterate that not all individuals who maltreat their children have maltreatment histories, and a fair number of parents who have been maltreated in their childhood do not go on to maltreat their children. Thus, a broad examination of potential risks and protective factors is warranted. Moreover, in individuals who experienced maltreatment in their childhood, there is often a considerable desire to create measurable change in how they choose to parent their own children, although this parental capacity to change may not always be realized (Martsolf \& Draucker, 2008; Swartz, Mercier, \& Curran, 2012) or be easily assessed (Cyr \& Alink, 2017).

It is important to implement assessment approaches that intentionally strengthen family capacities in order to assess potential resiliency factors. For example, to assess parental capacity to change in parents reported for child maltreatment, Cyr et al. (2015) implemented a strength-based, short-term attachment intervention (the Attachment Video-feedback Intervention of Moss et al., 2011), which was included in a parental capacity assessment protocol (PCA). They compared this protocol to either an assessment involving a psychoeducational intervention or a treatment as usual PCA with no intervention. One-year after the PCA, they found less recurrence of maltreatment in children of parents who were part of the Attachment Video-feedback Intervention group and more likely to be perceived by their PCA evaluators as capable of minimal standards of child care.

Maltreatment often occurs within the context of the parent-child relationship. Accordingly, several parenting intervention programs have been developed to enhance parental sensitivity and parent-child interactive quality with the aim of reducing the occurrence and transmission of maltreatment. For example, parent-child interaction therapy, an evidencebased parent-training program grounded on principals of social learning and attachment theories, has demonstrated efficacy in reducing the recurrence of CPS reports of physical abuse (Chaffin et al., 2004). While there are some studies that show demonstrated effectiveness in reducing child maltreatment, other randomized controlled trials in maltreating and at-risk families, as well as those at the general population, have not. Euser, Alink, Stoltenborgh, Bakermans-Kranenburg, and van IJzendoorn (2015) conducted a meta-analysis on the effectiveness of 20 intervention programs aiming to prevent maltreatment assessed using a randomized controlled trial. As the authors note, a rather gloomy picture emerges in which only 5 out of the 20 intervention programs were effective in preventing or reducing the risk of child maltreatment. Moderator analyses revealed that treatment effectiveness was higher in studies that provided parent training and nonsignificant in studies that focused on support exclusively. This finding points to an important target of intervention: strengthbased parent training, which at present seems the most promising strategy to prevent child maltreatment.

\section{Limitations and future directions}

The current synthesis provides a quantitative examination of the intergenerational transmission of maltreatment and has, as its strengths, a dual focus on addressing the role of methodological quality using a relatively large sample of studies from around the world. Despite these strengths, there are also several noteworthy limitations that should be addressed. First, although we had a relatively large number of studies examining the intergenerational transmission of maltreatment $(k=80)$, the series of meta-analyses on homotypic transmission for emotional abuse, sexual abuse, and neglect were based on a small group of studies ( $k$ ranged from 13 to 18). One consequence of moderator analyses when the sample size is small is low statistical power, and, therefore, the moderator analyses for emotional abuse, sexual abuse, and neglect should be considered exploratory.

Second, in the current study, maltreatment is treated as present versus absent and, thus, does not take severity or chronicity into account. Extant theory suggests that the severity and chronicity of maltreatment experiences in G2 can play a role in the proclivity to be abusive toward G3. Specifically, a dose-response hypothesis has been proposed (Rutter, Quinton, \& Liddle, 1983): the greater the dose of maltreatment in one generation, the higher the likelihood of transmission 
onto the next. Research supporting this claim, however, has been somewhat mixed. For example, Pears and Capaldi (2001) investigated the dose-response response hypothesis and found that parents who experienced severe physical punishment that resulted in injuries were more at risk of being abusive toward their own children than parents with less severe histories of physical abuse. Similarly, in a sample of 213 predominantly low-income African American mothers, Zuravin, McMillen, DePanfilis, and Risley-Curtiss (1996) observed an increased likelihood of intergenerational transmission of sexual abuse in women with more severe and chronic abuse exposure. However, they did not find a similar dose-response in the transmission of neglect or physical abuse. Consistent with this finding are studies by Caliso and Milner (1992), as well as Herrenkohl, Herrenkohl, and Toedter (1983), who failed to find support for the dose-response hypothesis. Future research is needed to disentangle these discrepant findings across all maltreatment types, and to conclusively determine whether maltreatment severity places an additive risk on the probability of intergenerational transmission of maltreatment. The protective role of reduced severity should also be examined. Specifically, is the cycle of maltreatment more likely to be broken in those who had less severe and/or frequent maltreatment experiences?

A third final limitation of the literature more generally is that research on the intergenerational transmission of maltreatment is correlational in nature, and thus, it cannot be inferred that maltreatment in one generation causes maltreatment in another. The current meta-analysis only confirms that an association is present. Moreover, this meta-analysis does not address potential mechanisms of transmission. For example, some researchers have suggested that intergenera-

\section{References}

Abolfotouh, M. A., El-Bourgy, M. D., Seif El Din, A. G., \& Mehanna, A. A. (2009). Corporal punishment: Mother's disciplinary behavior and child's psychological profile in Alexandria, Egypt. Journal of Forensic Nursing, 5, 5-17. doi:10.1111/j.1939-3938.2009.01025.x

Adamson, J. L. (1997). Predicting attachment and violence in relationships: An investigation across three generations. Dissertation Abstracts International Section A: Humanities and Social Sciences, 58, 3318.

Alink, L.R., Cyr, C., \& Madigan, S. (2019). The effect of maltreatment experiences on maltreating and dysfunctional parenting: A search for mechanisms. Development \& Psychopathology, 31, 1-7.

Alink, L. R., Euser, S., van IJzendoorn, M. H., \& Bakermans-Kranenburg, M. J. (2013). Is elevated risk of child maltreatment in immigrant families associated with socioeconomic status? Evidence from three sources. International Journal of Psychology, 48, 117-127. doi:10.1080/ 00207594.2012 .734622

Altemeier, W. A., O'Connor, S., Vietze, P. M., Sandler, H. M., \& Sherrod, K. B. (1982). Antecedents of child abuse. Journal of Pediatrics, 100, 823-829.

Appleyard, K., Berlin, L. J., Rosanbalm, K. D., \& Dodge, K. A. (2011). Preventing early child maltreatment: Implications from a longitudinal study of maternal sbuse history, substance use problems, and offspring victimization. Prevention Science, 12, 139-149.

Assini-Meytin, L. C., \& Green, K. M. (2015). Long-term consequences of adolescent parenthood among African-American urban youth: A propensity score matching approach. Journal of Adolescent Health, 56, 529535. doi:10.1016/j.jadohealth.2015.01.005 tional transmission associations may be partly, or entirely, explained by other factors, such as genetic inheritance, traits shared between G2 and G3, or other third variables (Widom \& Wilson, 2015). Devoted empirical searches for mechanisms of transmission, that is, the "how" and the "why" of this developmental pathway, should represent the future of research on the intergenerational transmission of maltreatment, so that preventive interventions can be appropriately targeted (see Alink, Cyr, \& Madigan, 2019).

\section{Conclusions}

The current study provides support for the cycle of maltreatment hypothesis, although effect sizes are small to moderate in magnitude. Parents with a maltreatment history are more than twice as likely to have children who also experience maltreatment. As Thornberry et al. (2012) aptly noted "if indeed there is clear and compelling evidence of intergenerational continuity, we then need to understand the mediating processes that link the generations in this regard" (p. 146). Accordingly, it is recommended that the field refocus its attention to uncovering and deepening understanding of mechanisms of intergenerational transmission. Knowledge about these mechanisms can directly inform and shape the development of future intervention and prevention strategies, which are urgently needed to break the cycle of maltreatment and ensure greater safety and enduring prosperity for the next generations of youth.

\section{Supplementary Material}

To view the supplementary material for this article, please visit https://doi.org/10.1017/S0954579418001700.

Avery, L., Hutchinson, K. D., \& Whitaker, K. (2002). Domestic violence and intergenerational rates of child sexual abuse: A case record analysis. Child and Adolescent Social Work Journal, 19, 77-90. doi:10.1023/ A:1014007507349

Azzopardi, C., Eirich, R., Rash, C.L., MacDonald, S., \& Madigan, S. (in press) A meta-analysis of the prevalence of child sexual abuse disclosure in forensic settings. Child Abuse \& Neglect. doi:10.1016/j.chiabu.2018.11.020

Bailey, J. A. (2007). Pathways to substance use among sexually abused girls Dissertation Abstracts International: Section B: The Sciences and Engineering, 68, 6354.

Bakermans-Kranenburg, M., Van IJzendoorn, M., \& Juffer, F. (2003). Less is more: Meta-analyses of sensitivity and attachment interventions in early childhood. Psychological Bulletin., 129(2), 195-215. doi:10.1037/00332909.129.2.195

Baldwin, J. A., \& Oliver, J. E. (1975). Epidemiology and family characteristics of severely-abused children. British Journal of Preventitive and Social Medicine, 29, 205-221.

Ball, J. D. (2009). Intergenerational transmission of abuse of incarcerated fathers: A study of the measurement of abuse. Journal of Family Issues, 30, 371-390. doi:10.1177/0192513X08326327

Banyard, V. L. (1997). The impact of childhood sexual abuse and family functioning on four dimensions of women's later parenting. Child Abuse \& Neglect, 21, 1095-1107.

Banyard, V. L., Williams, L. M., \& Siegel, J. A. (2003). The impact of complex trauma and depression on parenting: An exploration of mediating 
risk and protective factors. Child Maltreatment, 8, 334-349. doi:10.1177/ 1077559503257106

Barrett, B. (2009). The impact of childhood sexual abuse and other forms of childhood adversity on adulthood parenting. Journal of Child Sexual Abuse, 18, 489-512. doi:10.1080/10538710903182628

Bartlett, J. D., Kotake, C., Fauth, R., \& Easterbrooks, M. A. (2017). Intergenerational transmission of child abuse and neglect: Do maltreatment type, perpetrator, and substantiation status matter? Child Abuse \& Neglect, 63, 84-94. doi:10.1016/j.chiabu.2016.11.021

Beckerman, M., van Berkel, S. R., Mesman, J., \& Alink, L. R. (2017). The role of negative parental attributions in the associations between daily stressors, maltreatment history, and harsh and abusive discipline. Child Abuse \& Neglect, 64, 109-116. doi:10.1016/j.chiabu.2016.12.015

Belsky, J. (1993). Etiology of child maltreatment: A developmentalcological analysis. Psychological Bulletin, 114, 413-434. doi:10.1037/00332909.114.3.413

Ben-David, V., Jonson-Reid, M., Drake, B., \& Kohl, P. L. (2015). The association between childhood maltreatment experiences and the onset of maltreatment perpetration in young adulthood controlling for proximal and distal risk factors. Child Abuse \& Neglect, 46, 132-141. doi:10.1016/j.chiabu.2015.01.013

Berlin, L. J., Appleyard, K., \& Dodge, K. A. (2011). Intergenerational continuity in child maltreatment: Mediating mechanisms and implications for prevention. Child Development, 82, 162-176. doi:10.1111/j.14678624.2010.01547.x

Bernstein, D. P., Fink, L., Handelsman, L., Foote, J., Lovejoy, M., Wenzel, K., . . \& Ruggiero, J. (1994). Initial reliability and validity of a new retrospective measure of child abuse and neglect. The American journal of psychiatry, 151(8). doi: 10.1176/ajp.151.8.1132

Bert, S. C., Guner, B. M., \& Lanzi, R. G. (2009). The influence of maternal history of abuse on parenting knowledge and behavior. Family Relations, 58, 176-187. doi:10.1111/j.1741-3729.2008.00545.x

Berzenski, S. R., Yates, T. M., \& Egeland, B. (2014). A multidimensional view of continuity in intergenerational transmission of child maltreatment. In J. E. Korbin \& R. D. Krugman (Eds.), Handbook of child maltreatment (pp. 115-129). Dordrecht: Springer Netherlands.

Borenstein, M., Cooper, H., Hedges, L., \& Valentine, J. (2009). Effect sizes for continuous data. In Cooper H., Hedges L.V., \& Valentine J.C. (Eds.), The handbook of research synthesis and meta-analysis (2nd ed.). New York, NY: Russell Sage Foundation.

Borenstein, M., Hedges, L.V., Higgins, J.P., \& Rothstein, H.R. (2014). Comprehensive Meta-Analysis, Version 3. Englewood, NJ: Biostat.

Bosquet Enlow, M., Devick, K. L., Brunst, K. J., Lipton, L. R., Coull, B. A., \& Wright, R. J. (2017). Maternal lifetime trauma exposure, prenatal cortisol, and infant negative affectivity. Infancy, 22, 492-513. doi:10.1111/ infa. 12176

Brodsky, B. S., Mann, J. J., Stanley, B., Tin, A., Oquendo, M., Birmaher, B., ... Brent, D. (2008). Familial transmission of suicidal behavior: Factors mediating the relationship between childhood abuse and offspring suicide attempts. Journal of Clinical Psychiatry, 69, 584-596.

Brown, J., Cohen, P., Johnson, J. G., \& Salzinger, S. (1998). A longitudinal analysis of risk factors for child maltreatment: Findings of a 17-year prospective study of officially recorded and self-reported child abuse and neglect. Child Abuse \& Neglect, 22, 1065-1078.

Caliso, J. A., \& Milner, J. S. (1992). Childhood history of abuse and child abuse screening. Child Abuse \& Neglect, 16, 647-659. doi:10.1016/ 0145-2134\%2892\%2990103-X

Caykoylu, A., Ibiloglu, A. O., Taner, Y., Potas, N., \& Taner, E. (2011). The correlation of childhood physical abuse history and later abuse in a group of Turkish population. Journal of Interpersonal Violence, 26, 34553475. doi: $10.1177 / 0886260511403748$

Chaffin, M., Silovsky, J. F., Funderburk, B., Valle, L. A., Brestan, E. V., Balachova, T., . . . Bonner, B. L. (2004). Parent-child interaction therapy with physically abusive parents: Efficacy for reducing future abuse reports. Journal of Consulting and Clinical Psychology, 72, 500-510. doi:10.1037/0022-006X.72.3.500

Choi, K. W., Houts, R., Arseneault, L., Pariante, C., Sikkema, K. J., \& Moffitt, T. E. (2018). Maternal depression in the intergenerational transmission of childhood maltreatment and its sequelae: Testing postpartum effects in a longitudinal birth cohort. Development and Psychopathology. Advance online publication. doi:10.1017/S0954579418000032

Cicchetti, D., Rogosch, F. A., \& Toth, S. L. (2006). Fostering secure attachment in infants in maltreating families through preventive interventions. Development and Psychopathology, 18, 623-649.
Clément, M. E., \& Bouchard, C. (2005). Predicting the use of single versus multiple types of violence towards children in a representative sample of Quebec families. Child Abuse \& Neglect, 29, 1121-1139.

Cohen, J. (1992). A power primer. Psychological Bulletin, 112, 155-159.

Cohen, L. R., Hien, D. A., \& Batchelder, S. (2008). The impact of cumulative maternal trauma and diagnosis on parenting behavior. Child Maltreatment, 13, 27-38. doi:10.1177/1077559507310045

Cole, P. M., Woolger, C., Power, T. G., \& Smith, K. D. (1992). Parenting difficulties among adult survivors of father-daughter incest. Child Abuse \& Neglect, 16, 239-249.

Coohey, C., \& Braun, N. (1997). Toward an integrated framework for understanding child physical abuse. Child Abuse \& Neglect, 21, 1081-1094.

Cort, N. A., Toth, S. L., Cerulli, C., \& Rogosch, F. (2011). Maternal intergenerational transmission of childhood multitype maltreatment. Journal of Aggression, Maltreatment \& Trauma, 20, 20-39. doi:10.1080/ 10926771.2011 .537740

Covell, K., Grusec, J. E., \& King, G. (1995). The intergenerational transmission of maternal discipline and standards for behavior. Social Development, 4, 32-43. doi:10.1111/j.1467-9507.1995.tb00049.x

Coxell, A., King, M., Mezey, G., \& Gordon, D. (1999). Lifetime prevalence, characteristics, and associated problems of non-consensual sex in men: Cross sectional survey. BMJ, 318, 846-850.

Crombach, A., \& Bambonye, M. (2015). Intergenerational violence in Burundi: Experienced childhood maltreatment increases the risk of abusive child rearing and intimate partner violence. European Journal of Psychotraumatology, 6, 26995. doi:10.3402/ejpt.v6.26995

Curtis, G. C. (1963). Violence breeds violence-Perhaps? American Journal of Psychiatry, 120, 386-387. doi:10.1176/ajp.120.4.386

Cyr, C., \& Alink, L. R. (2017). Child maltreatment: The central roles of parenting capacities and attachment. Current Opinion in Psychology, 15, 81-86. doi:10.1016/j.copsyc.2017.02.002

Cyr, C., Paquette, D., Lopez, L., \& Dubois-Comtois, K. (2015). An attachment-based intervention protocol for the assessment of parenting capacities in child welfare cases. In M. Bakermans-Kranenburg (Chair), Symposium presented at the Society for Research in Child Development, Philadelphia, Pennsylvania.

Danese, A., \& Tan, M. (2014). Childhood maltreatment and obesity: Systematic review and meta-analysis. Molecular Psychiatry, 19, 544-554. doi:10.1038/mp.2013.54

DeBruyn, L. M., Lujan, C. C., \& May, P. A. (1992). A comparative study of abused and neglected American Indian children in the southwest. Social Science \& Medicine, 35, 305-315.

Dias, A., Sales, L., Cardoso, R. M., \& Kleber, R. (2014). Childhood maltreatment in adult offspring of Portuguese war veterans with and without PTSD. European Journal of Psychotraumatology, 5, 20198. doi:10.3402/ejpt.v5.20198

Dietz, T. L. (2000). Disciplining children: Characteristics associated with the use of corporal punishment. Child Abuse \& Neglect, 24, 1529-1542.

DiLillo, D., Tremblay, G. C., \& Peterson, L. (2000). Linking childhood sexual abuse and abusive parenting: The mediating role of maternal anger. Child Abuse \& Neglect, 24, 767-779.

Disbrow, M. A., Doerr, H., \& Caulfield, C. (1977). Measuring the components of parents' potential for child abuse and neglect. Child Abuse \& Neglect, 1, 279-296. doi:10.1016/0145-2134(77)90003-5

Dixon, L., Browne, K., \& Hamilton-Giachritsis, C. (2005). Risk factors of parents abused as children: A mediational analysis of the intergenerational continuity of child maltreatment (Part I). Journal of Child Psychology and Psychiatry, 46, 47-57. doi:10.1111/j.1469-7610. 2004.00339. $\mathrm{x}$

Dixon, L., Hamilton-Giachritsis, C., \& Browne, K. (2005). Attributions and behaviours of parents abused as children: A mediational analysis of the intergenerational continuity of child maltreatment (Part II). Journal of Child Psychology and Psychiatry, 46, 58-68. doi:10.1111/j.14697610.2004.00340.x

Dubowitz, H., Black, M. M., Kerr, M. A., Hussey, J. M., Morrel, T. M., Everson, M. D., \& Starr, R. H., Jr. (2001). Type and timing of mothers' victimization: Effects on mothers and children. Pediatrics, 107, 728-735.

Dubowitz, H., Hampton, R. L., Bithoney, W. G., \& Newberger, E. H. (1987). Inflicted and noninflicted injuries: Differences in child and familial characteristics. American Journal of Orthopsychiatry, 57, 525-535. doi:10.1111/j.1939-0025.1987.tb03568.x

Duckworth, D. N. (1997). Referential activity and the cycle of psychological and physical abuse. Dissertation Abstracts International: Section B: The Sciences and Engineering, 58, 2178. 
Duhamel, M., \& Fortin, A. (2004). Justification de la violence envers l'enfant chez des mères victimes de violence conjugale. Canadian Journal of Community Mental Health, 23, 47-63. doi:10.7870/cjcmh-20040004

Duval, S., \& Tweedie, R. (2000). Trim and Fill: A Simple Funnel-Plot-Based Method of Testing and Adjusting for Publication Bias in Meta-Analysis. Biometrics, 56(2), 455-463. doi:10.1111/j.0006-341X.2000.00455.X

Dworsky, A. (2015). Child welfare services involvement among the children of young parents in foster care. Child Abuse \& Neglect, 45, 68-79. doi:10.1016/j.chiabu.2015.04.005

Egeland, B., \& Susman-Stillman, A. (1996). Dissociation as a mediator of child abuse across generations. Child Abuse \& Neglect, 20, 11231132. doi:10.1016/0145-2134\%2896\%2900102-0

Ehrle, J., \& Geen, R. (2002). Kin and non-kin foster care-findings from a national survey. Children and Youth Services Review, 24, 15-35. doi:10.1016/S0190-7409(01)00166-9

Ertem, I. O., Leventhal, J. M., \& Dobbs, S. (2000). Intergenerational continuity of child physical abuse: How good is the evidence? Lancet, 356, 814-819.

Esaki, N. (2008). The effect of maternal childhood abuse on parenting attitude and behavior. Dissertation Abstracts International Section A: $\mathrm{Hu}$ manities and Social Sciences, 69, 1540.

Éthier, L. S., Lacharité, C., \& Couture, G. (1995). Childhood adversity, parental stress, and depression of negligent mothers. Child Abuse \& Neglect, 19, 619-632. doi:10.1016/0145-2134(95)00020-9

Euser, S., Alink, L. R., Pannebakker, F., Vogels, T., Bakermans-Kranenburg, M. J., \& van IJzendoorn, M. H. (2013). The prevalence of child maltreatment in the Netherlands across a 5-year period. Child Abuse \& Neglect, 37, 841-851. doi:10.1016/j.chiabu.2013.07.004

Euser, S., Alink, L. R., Stoltenborgh, M., Bakermans-Kranenburg, M. J., \& van IJzendoorn, M. H. (2015). A gloomy picture: A meta-analysis of randomized controlled trials reveals disappointing effectiveness of programs aiming at preventing child maltreatment. BMC Public Health, 15, 1068. doi:10.1186/s12889-015-2387-9

Falbo, G., Caminha, F., Aguiar, F., Albuquerque, J., Chacon, M. D., Miranda, S., \& Marques, S. (2004). Incidence of child and adolescent abuse among incarcerated females in the northeast of Brazil. Journal of Tropical Pediatrics, 50, 292-296.

Fang, X., Brown, D. S., Florence, C. S., \& Mercy, J. A. (2012). The economic burden of child maltreatment in the United States and implications for prevention. Child Abuse \& Neglect, 36, 156-165. doi:10.1016/ j.chiabu.2011.10.006

Felitti, V. J., Anda, R. F., Nordenberg, D., Williamson, D. F., Spitz, A. M., Edwards, V., . . . Marks, J. S. (1998). Relationship of Childhood Abuse and Household Dysfunction to Many of the Leading Causes of Death in Adults: The Adverse Childhood Experiences (ACE) Study. American Journal of Preventive Medicine, 14(4), 245-258. doi:10.1016/S07493797(98)00017-8

Ferrari, A. M. (2002). The impact of culture upon child rearing practices and definitions of maltreatment. Child Abuse \& Neglect, 26, 793-813.

Finkelhor, D., Hotaling, G., Lewis, I. A., \& Smith, C. (1990). Sexual abuse in a national survey of adult men and women: Prevalence, characteristics, and risk factors. Child Abuse \& Neglect, 14, 19-28.

Finkelhor, D., Moore, D., Hamby, S. L., \& Straus, M. A. (1997). Sexually abused children in a national survey of parents: Methodological issues. Child Abuse \& Neglect, 21, 1-9.

Fleming, J., Mullen, P., \& Bammer, G. (1997). A study of potential risk factors for sexual abuse in childhood. Child Abuse \& Neglect, 21, 49-58.

Folsom, W. S., Christensen, M. L., Avery, L., \& Moore, C. (2003). The cooccurrence of child abuse and domestic violence: An issue of service delivery for social service professionals. Child \& Adolescent Social Work Journal, 20, 375-387. doi:10.1023/A:1026047929774

Francis, K. J., \& Wolfe, D. A. (2008). Cognitive and emotional differences between abusive and non-abusive fathers. Child Abuse \& Neglect, 32, 1127-1137. doi:10.1016/j.chiabu.2008.05.007

Fujiwara, T., Okuyama, M., \& Izumi, M. (2010). The cycle of violence: Childhood abuse history, domestic violence and child maltreatment among Japanese mothers. Psychologia, 53, 211-224. doi:10.2117/psysoc. 2010.211

Fuller, B. E., Chermack, S. T., Cruise, K. A., Kirsch, E., Fitzgerald, H. E., \& Zucker, R. A. (2003). Predictors of aggression across three generations among sons of alcoholics: Relationships involving grandparental and pa- rental alcoholism, child aggression, marital aggression and parenting practices. Journal of Studies on Alcohol, 64, 472-483.

Gage, A. J., \& Silvestre, E. A. (2010). Maternal violence, victimization, and child physical punishment in Peru. Child Abuse \& Neglect, 34, 523-533. doi:10.1016/j.chiabu.2009.12.004

Garbarino, J., \& Gilliam, G. (1980). Understanding abusive families. Lanham, MD: Lexington Books.

Glasser, M., Kolvin, I., Campbell, D., Glasser, A., Leitch, I., \& Farrelly, S. (2001). Cycle of child sexual abuse: Links between being a victim and becoming a perpetrator. British Journal of Psychiatry, 179, 482-494. doi:10.1192/bjp.179.6.482

Goodwin, J., McCarthy, T., \& DiVasto, P. (1981). Prior incest in mothers of abused children. Child Abuse \& Neglect, 5, 87-95. doi:10.1016/01452134(81)90025-9

Grusec, J. E., Covell, K., \& Paucha, P. (1991). The intergenerationl transmission of discipline techniques and associated belief systems. Paper presented at the Biennial Meeting of Society for Research in Child Development, Seattle.

Haapasalo, J., \& Aaltonen, T. (1999). Mothers' abusive childhood predicts child abuse. Child Abuse Review, 8, 231-250. doi:10.1002/(SICI)10990852(199907/08)8:4<231::AID-CAR547>3.0.CO;2-C

Harden, B. J., Buhler, A., \& Parra, L. J. (2016). Maltreatment in infancy: A developmental perspective on prevention and intervention. Trauma, Violence, \& Abuse, 17, 366-386. doi:10.1177/1524838016658878

Healy, K., Kennedy, R., \& Sinclair, J. (1991). Child physical abuse observed: Comparison of families with and without history of child abuse treated in an in-patient family unit. British Journal of Psychiatry, 158, 234-237.

Hedges, L.V. \& Olkin, I. (1985). Statistical Methods for Meta-Analysis. New York, NY: Academic Press.

Heller, S. S., Larrieu, J. A., D’Imperio, R., \& Boris, N. W. (1999). Research on resilience to child maltreatment: Empirical considerations. Child Abuse \& Neglect, 23, 321-338.

Hemenway, D., Solnick, S., \& Carter, J. (1994). Child-rearing violence. Child Abuse \& Neglect, 18, 1011-1020. doi:10.1016/0145-2134\% 2894\%2990126-0

Henry, B., Moffitt, T. E., Caspi, A., Langley, J., \& Silva, P. A. (1994). On the "remembrance of things past": A longitudinal evaluation of the retrospective method. Psychological Assessment, 6, 92-101.

Herrenkohl, E. C., Herrenkohl, R. C., \& Toedter, L. J. (1983). Perspectives on the intergenerational transmission of abuse. In D. Finkelhor, R. J. Gelles, G. T. Hotaling, \& M. A. Straus (Eds.), The dark side of families: Current family violence research (pp. 305-316). Beverly Hills, CA: Sage.

Herrenkohl, T. I., Klika, J., Brown, E. C., Herrenkohl, R. C., \& Leeb, R. T. (2013). Tests of the mitigating effects of caring and supportive relationships in the study of abusive disciplining over two generations. Journal of Adolescent Health, 53. doi:10.1016/j.jadohealth.2013.04.009

Heyman, R. E., \& Slep, A. M. S. (2002). Do child abuse and interparental violence lead to adulthood family violence? Journal of Marriage and Family, 64, 864-870.

Hughes, H. M., Parkinson, D., \& Vargo, M. (1989). Witnessing spouse abuse and experiencing physical abuse: A "double whammy"? Journal of Family Violence, 4, 197-209.

Hughes, K., Bellis, M. A., Hardcastle, K. A., Sethi, D., Butchart, A., Mikton, C., ... Dunne, M. P. (2017). The effect of multiple adverse childhood experiences on health: A systematic review and meta-analysis. Lancet Public Health, 2, e356-e366. doi:10.1016/S2468-2667(17)30118-4

Hunter, R. S., \& Kilstrom, N. (1979). Breaking the cycle in abusive families. American Journal of Psychiatry, 136, 1320-1322.

Hussey, J. M., Chang, J. J., \& Kotch, J. B. (2006). Child maltreatment in the United States: Prevalence, risk factors, and adolescent health consequences. Pediatrics, 118, 933-942. doi:10.1542/peds.2005-2452

Ioannidis, J. P. A. (2005). Why most published research findings are false PLOS Medicine, 2, e124.

Isumi, A., \& Fujiwara, T. (2016). Association of adverse childhood experiences with shaking and smothering behaviors among Japanese caregivers. Child Abuse \& Neglect, 57, 12-20. doi:10.1016/j.chiabu. 2016.05.002

Jackson, S., Thompson, R. A., Christiansen, E. H., Colman, R. A., Wyatt, J., Buckendahl, C. W., . . . Peterson, R. (1999). Predicting abuse-prone parental attitudes and discipline practices in a nationally representative sample. Child Abuse \& Neglect, 23, 15-29. 
Jaffee, S. R., Bowes, L., Ouellet-Morin, I., Fisher, H. L., Moffitt, T. E., Merrick, M. T., \& Arseneault, L. (2013). Safe, stable, nurturing relationships break the intergenerational cycle of abuse: A prospective nationally representative cohort of children in the United Kingdom. Journal of Adolescent Health, 53(4, Suppl.), S4-S10. doi:10.1016/j.jadohealth. 2013.04.007

Jamal, F., Dufour, S., Clement, M., \& Chamberland, C. (2011). Linking the perceived legitimacy of the violence experienced by Quebec fathers during their childhood to the violence currently experienced by children in their family. Revue de Psychoeducation, 40, 175-190.

Joo, B. (2008). The relationship between past experiences of child abuse and current parenting practices among incarcerated women. Dissertation $A b$ stracts International: Section B: The Sciences and Engineering, 69, 5781.

Julious, S. A. (2004). Using confidence intervals around individual means to assess statistical significance between two means. Pharmaceutical Statistics, 3, 217-222. doi:10.1002/pst.126

Kaufman, J., \& Zigler, E. (1987). Do abused children become abusive parents? American Journal of Orthopsychiatry, 57, 186-192. doi:10.1111/ j.1939-0025.1987.tb03528.x

Kaufman, J., \& Zigler, E. (1989). The intergenerational transmission of child abuse. In D. Cicchetti \& V. Carlson (Eds.), Child maltreatment: Theory and research on the causes and consequences of child abuse and neglect (pp. 129-150). New York: Cambridge University Press.

Kempe, C. H., Silverman, F. N., Steele, B. F., Droegemueller, W., \& Silver, H. K. (1962). The battered-child syndrome. Journal of the American Medical Association, 181, 17-24.

Kim, H. K., Capaldi, D. M., Pears, K. C., Kerr, D. C. R., \& Owen, L. D. (2009). Intergenerational transmission of internalising and externalising behaviours across three generations: Gender-specific pathways. Criminal Behaviour and Mental Health, 19, 125-141. doi:10.1002/cbm.708

Kim, H. K., Pears, K. C., Fisher, P. A., Connelly, C. D., \& Landsverk, J. A. (2010). Trajectories of maternal harsh parenting in the first 3 years of life. Child Abuse \& Neglect, 34, 897-906.

Kim, J. (2009). Type-specific intergenerational transmission of neglectful and physically abusive parenting behaviors among young parents. Children and Youth Services Review, 31, 761-767. doi:10.1016/j.childyouth.2009.02.002

Kim, J. H., Leung, M. C. M., Yip, B. H., Su, X., \& Griffiths, S. M. (2017). Exploring cross-generational adult drinking patterns and physical child maltreatment: A study of Hong Kong adults. Public Health, 144, 143146. doi:10.1016/j.puhe.2017.01.014

Kim, K., Noll, J. G., Putnam, F. W., \& Trickett, P. K. (2007). Psychosocial characteristics of nonoffending mothers of sexually abused girls: Findings from a prospective, multigenerational study. Child Maltreatment, 12, 338-351. doi:10.1177/1077559507305997

Kim, K., Trickett, P. K., \& Putnam, F. W. (2010). Childhood experiences of sexual abuse and later parenting practices among non-offending mothers of sexually abused and comparison girls. Child Abuse \& Neglect, 34, 610-622. doi:10.1016/j.chiabu.2010.01.007

Kotelchuck, M. (1982). Child abuse and neglect: Prediction and misclassification. In J. R. H. Starr (Ed.), Child abuse prediction: Policy implications (pp. 67-104). Cambridge, MA: Ballinger.

Kovan, N. M. (2009). The continuity of parenting across two generations using a prospective, longitudinal design (Unpublished doctoral dissertation, University of Minnesota).

Leifer, M., Kilbane, T., Jacobsen, T., \& Grossman, G. (2004). A three-generational study of iransmission of risk for sexual abuse. Journal of Clinical Child and Adolescent Psychology, 33, 662-672.

Lesnik-Oberstein, M., Koers, A. J., \& Cohen, L. (1995). Parental hostility and its sources in psychologically abusive mothers: A test of the threefactor theory. Child Abuse \& Neglect, 19, 33-49.

Leventhal, J. M. (1998). Epidemiology of sexual abuse of children: Old problems, new directions. Child Abuse \& Neglect, 22, 481-491.

Libby, A. M., Orton, H. D., Beals, J., Buchwald, D., \& Manson, S. M. (2008). Childhood abuse and later parenting outcomes in two American Indian tribes. Child Abuse \& Neglect, 32, 195-211. doi:10.1016/ j.chiabu.2007.07.006

Lippert, T., Cross, T. P., Jones, L., \& Walsh, W. (2009). Telling interviewers about sexual abuse: Predictors of child disclosure at forensic interviews. Child Maltreatment, 14, 100-113. doi:10.1177/ 1077559508318398

Lucas-Thompson, R. G., Goldberg, W. A., \& Prause, J. (2010). Maternal work early in the lives of children and its distal associations with achieve- ment and behavior problems: A meta-analysis. Psychological Bulletin, 136, 915-942. doi:10.1037/a0020875

Lukek, S. P. (2015). Intergenerational transfer of parenting styles: Correlations between experience of punitive discipline in childhood, opinion regarding discipline methods, and context of parenting. Journal of Aggression Maltreatment \& Trauma, 24, 299-318. doi:10.1080/10926771. 2015.1009600

Macias, S. B. (2004). The intergenerational transmission of abuse: The relationship between maternal abuse history, parenting stress, child symptomatology, and treatment attrition. Dissertation Abstracts International: Section B: The Sciences and Engineering, 65, 4838.

Madigan, S., Brumariu, L. E., Villani, V., Atkinson, L., \& Lyons-Ruth, K. (2016). Representational and questionnaire measures of attachment: A meta-analysis of relations to child internalizing and externalizing problems. Psychological Bulletin, 142, 367-399. doi:10.1037/bul0000029

Maida, A. M., Molina, M. E., Basualto, C., Bahamondes, C., Leonvendagar, X., \& Abarca, C. (2005). La experiencia de abuso en las madres: ¿Es un predictor de abuso sexual de sus hijos? Revista chilena de pediatría, 76, 41. doi:10.4067/S0370-41062005000100005

Martsolf, D. S., \& Draucker, C. B. (2008). The legacy of childhood sexual abuse and family adversity. Journal of Nursing Scholarship, 40, 333 340. doi:10.1111/j.1547-5069.2008.00247.x

Massé, R. (1994). Antécédents de violence et transmission intergénérationnelle de la maltraitance. PRISME Psychiatrie, recherche et intervention en santé mentale de l'enfant, 4, 239-249.

Matos, A. L., Moleiro, C., \& Dias, J. G. (2014). Clusters of abusive parenting: A latent class analysis of families referred to Child Protective Services in Portugal. Child Abuse \& Neglect, 38, 2053-2061. doi:10.1016/ j.chiabu.2014.10.018

McCloskey, L. A., \& Bailey, J. A. (2000). The intergenerational transmission of risk for child sexual abuse. Journal of Interpersonal Violence, 15, 1019-1035.

Medley, A., \& Sachs-Ericsson, N. (2009). Predictors of parental physical abuse: The contribution of internalizing and externalizing disorders and childhood experiences of abuse. Journal of Affective Disorders, 113, 244-254. doi:10.1016/j.jad.2008.05.020

Mennen, F. E., Kim, K., Sang, J., \& Trickett, P. K. (2010). Child neglect: Definition and identification of youth's experiences in official reports of maltreatment. Child Abuse \& Neglect, 34, 647-658. doi:10.1016/ j.chiabu.2010.02.007

Miech, R. A., Caspi, A., Moffitt, T. E., Wright, B. R. E., \& Silva, P. A. (1999). Low socioeconomic status and mental disorders: A longitudinal study of selection and causation during young adulthood. American Journal of Sociology, 104, 1096-1131. doi:10.1086/210137

Milaniak, I., \& Widom, C. S. (2015). Does child abuse and neglect increase risk for perpetration of violence inside and outside the home? Psychology of Violence, 5, 246-255. doi:10.1037/a0037956

Militza, A. M., Rojas, M. E., \& Liliana, V. G. (2010). Violencia trans e intergeneracional en madres con hijos adolescentes en tres ciudades de la sierra peruana. Anales de Salud Mental, 26, 9-18.

Miller, B. A., Smyth, N. J., \& Mudar, P. J. (1999). Mothers' alcohol and other drug problems and their punitiveness toward their children. Journal of Studies on Alcohol, 60, 632-642.

Miller, P. M. (2000). Differences in cognitive-emotional functioning as a mechanism in the cycle of violence among college males abused as children. Dissertation Abstracts International: Section B: The Sciences and Engineering, 62, 5384.

Milner, J. S. (1986). The Child Abuse Potential Inventory: Manual (2nd ed.) Webster, NC: Psytec.

Mirabella-Beck, J. (1999). The relationship between maternal history of victimization, current social supports, and abusive parenting behaviors: A Winnicottian perspective. Dissertation Abstracts International Section A: Humanities and Social Sciences, 60, 3528.

Moss, E., Dubois-Comtois, K., Cyr, C., Tarabulsy, G. M., St.-Laurent, D., \& Bernier, A. (2011). Efficacy of a home-visiting intervention aimed at improving maternal sensitivity, child attachment, and behavioral outcomes for maltreated children: A randomized control trial. Development and Psychopathology, 23, 195-210. doi:10.1017/S09545794 10000738

Muller, R. T., Hunter, J. E., \& Stollak, G. (1995). The intergenerational transmission of corporal punishment-A comparison of social-learning and temperament models. Child Abuse \& Neglect, 19, 1323-1335.

Murphy-Cowan, T., \& Stringer, M. (1999). Physical punishment and the parenting cycle: A survey of Northern Irish parents. Journal of Community 
\& Applied Social Psychology, 9, 61-71. doi:10.1002/(SICI)10991298(199901/02)9:1<61::AID-CASP502>3.0.CO;2-P

Narayan, A. J., Kalstabakken, A. W., Labella, M. H., Nerenberg, L. S., Monn, A. R., \& Masten, A. S. (2017). Intergenerational continuity of adverse childhood experiences in homeless families: Unpacking exposure to maltreatment versus family dysfunction. American Journal of Orthopsychiatry, 87, 3-14. doi:10.1037/ort0000133

Newcomb, M. D., \& Locke, T. F. (2001). Intergenerational cycle of maltreatment: A popular concept obscured by methodological limitations. Child Abuse \& Neglect, 25, 1219-1240. doi:10.1016/S0145-2134\% $2801 \% 2900267-8$

Ney, P. G. (1988). Transgenerational child abuse. Child Psychiatry and Human Development, 18, 151-168. doi:10.1007/BF00709728

Noll, J. G., Trickett, P. K., Harris, W. W., \& Putnam, F. W. (2009). The cumulative burden borne by offspring whose mothers were sexually abused as children: Descriptive results from a multigenerational study. Journal of Interpersonal Violence, 24, 424-449. doi:10.1177/ 0886260508317194

Norman, R. E., Byambaa, M., De, R., Butchart, A., Scott, J., \& Vos, T. (2012). The long-term health consequences of child physical abuse, emotional abuse, and neglect: A systematic review and meta-analysis. PLOS Medicine, 9, e1001349. doi:10.1371/journal.pmed.1001349

Oates, R. K., Tebbutt, J., Swanston, H., Lynch, D. L., \& O’Toole, B. I. (1998). Prior childhood sexual abuse in mothers of sexually abused children. Child Abuse \& Neglect, 22, 1113-1118.

Ozcan, N. K., Boyacioglu, N. E., Enginkaya, S., Bilgin, H., \& Tomruk, N. B. (2016). The relationship between attachment styles and childhood trauma: A transgenerational perspective-A controlled study of patients with psychiatric disorders. Journal of Clinical Nursing, 25, 2357-2366. doi:10.1111/jocn.13274

Pears, K. C., \& Capaldi, D. M. (2001). Intergenerational transmission of abuse: A two-generational prospective study of an at-risk sample. Child Abuse \& Neglect, 25, 1439-1461. doi:10.1016/S0145-2134\%2801 $\% 2900286-1$

Pelton, L. H. (2015). The continuing role of material factors in child maltreatment and placement. Child Abuse \& Neglect, 41, 30-39. doi:10.1016/ j.chiabu.2014.08.001

Peltonen, K., Ellonen, N., Poso, T., \& Lucas, S. (2014). Mothers' self-reported violence toward their children: A multifaceted risk analysis. Child Abuse \& Neglect, 38, 1923-1933. doi:10.1016/j.chiabu.2014.10.016

Perepletchikova, F., Ansell, E., \& Axelrod, S. (2012). Borderline personality disorder features and history of childhood maltreatment in mothers involved with Child Protective Services. Child Maltreatment, 17, 182-190.

Pérez, E., \& de Paul, J. (2003). Intergenerational transmission of physical abuse: A two generation study. Psicothema, 15, 452-457.

Plant, D. T., Barker, E. D., Waters, C. S., Pawlby, S., \& Pariante, C. M. (2013). Intergenerational transmission of maltreatment and psychopathology: The role of antenatal depression. Psychological Medicine, 43, 519-528.

Pollak, S. D., Nelson, C. A., Schlaak, M. F., Roeber, B. J., Wewerka, S. S., Wiik, K. L., . . Gunnar, M. R. (2010). Neurodevelopmental effects of early deprivation in postinstitutionalized children. Child Development, 81, 224-236. doi:10.1111/j.1467-8624.2009.01391.x

Putnam-Hornstein, E., Cederbaum, J. A., King, B., Eastman, A. L., \& Trickett, P. K. (2015). A population-level and longitudinal study of adolescent mothers and intergenerational maltreatment. American Journal of Epidemiology, 181, 496-503.

Ramirez, C., Pinzon-Rondon, A. M., \& Botero, J. C. (2011). Contextual predictive factors of child sexual abuse: The role of parent-child interaction. Child Abuse \& Neglect, 35, 1022-1031. doi:10.1016/j.chiabu. 2011.10.004

Renner, L. M., \& Slack, K. S. (2006). Intimate partner violence and child maltreatment: Understanding intra- and intergenerational connections. Child Abuse \& Neglect, 30, 599-617. doi:10.1016/j.chiabu.2005.12.005

Rijlaarsdam, J., Stevens, G., Jansen, P. W., Ringoot, A. P., Jaddoe, V. W. V., Hofman, A., . . . Tiemeier, H. (2014). Maternal childhood maltreatment and offspring emotional and behavioral problems: Maternal and paternal mechanisms of risk transmission. Child Maltreatment, 19, 67-78.

Rikić, J., Beljan, P., Milosevic, M., Miskulin, I., Miskulin, M., \& Mujkic, A. (2017). Transgenerational transmission of violence among parents of preschool children in Croatia. Acta Clinica Croatica, 56, 478-486. doi:10.20471/acc.2017.56.03.15

Rodriguez, C. M., \& Sutherland, D. (1999). Predictors of parents' physical disciplinary practices. Child Abuse \& Neglect, 23, 651-657.
Romano, E. \& De Luca, R. V. (2001). Male sexual abuse: A review of effects, abuse characteristics, and links with later psychological functioning. Aggression and Violent Behavior, 6, 55-78. doi:10.1016/S13591789(99)00011-7

Romero, J. C. G., \& Armenta, M. F. (2005). The consequences of child abuse: A study with Mexican mothers. Revista Mexicana de Psicologia, $22,363-374$.

Rosenthal, R. (1995). Writing meta-analytic reviews. Psychological Bulletin., 118(2), 183-192. doi:10.1037/0033-2909.118.2.183

Rutter, M., Quinton, D., \& Liddle, C. (1983). Parenting in two generations: Looking backwards and looking forwards. Families at Risk, 8, 60-98.

Sahin, E. M., \& Yetim, D. (2011). Physical child abuse and causative factors in Edirne, Turkey. Turkish Journal of Pediatrics, 53, 375-380.

Saile, R., Ertl, V., Neuner, F., \& Catani, C. (2014). Does war contribute to family violence against children? Findings from a two-generationa multi-informant study in Northern Uganda. Child Abuse \& Neglect, 38, 135-146. doi:10.1016/j.chiabu.2013.10.007

Salzinger, S., Feldman, R. S., Hammer, M., \& Rosario, M. (1992). Constellations of family violence and their differential-effects on children's behavioral disturbance. Child \& Family Behavior Therapy, 14, 23-41.

Savage, L. E., Tarabulsy, G. M., Pearson, J., Collin-Vézina, D., \& Gagné, L. M. (2019). Maternal antecedents of childhood maltreatment and later parenting outcome: A meta-analysis. Development and Psychopathology $31,9-21$.

Scaramella, L. V., \& Conger, R. D. (2003). Intergenerational continuity of hostile parenting and its consequences: The moderating influence of children's negative emotional reactivity. Social Development, 12, 420-439. doi:10.1111/1467-9507.00241

Schluter, P. J., Tautolo, E., \& Paterson, J. (2011). Experience of physical abuse in childhood and perpetration of physical punishment and violence in adulthood amongst fathers: Findings from the Pacific Islands Families Study. Pacific Health Dialog, 17, 148-192.

Schofield, T. J., Lee, R. D., \& Merrick, M. T. (2013). Safe, stable, nurturing relationships as a moderator of intergenerational continuity of child maltreatment: A meta-analysis. Journal of Adolescent Health, 53(4, Suppl.), S32-S38. doi:10.1016/j.jadohealth.2013.05.004

Seay, D. M., Jahromi, L. B., Umana-Taylor, A. J., \& Updegraff, K. A. (2016) Intergenerational transmission of maladaptive parenting strategies in families of adolescent mothers: Effects from grandmothers to young children. Journal of Abnormal Child Psychology, 44, 1097-1109. doi:10.1007/ s10802-015-0091-y

Sedlak, A. J., Mettendburg, J., Basena, M., Petta, I., McPherson, K., Green, A., \& Li, S. (2010). Fourth National Incidence Study of Child Abuse and Neglect (NIS-4): Report to Congress, Executive Summary. Washington, DC: US Department of Health and Human Services, Administration for Children and Families.

Shenk, C. E., Ammerman, R. T., Teeters, A. R., Bensman, H. E., Allen, E. K., Putnam, F. W., \& Van Ginkel, J. B. (2017). History of maltreatment in childhood and subsequent parenting stress in at-risk, first-time mothers: Identifying points of intervention during home visiting. Prevention Science, 18, 361-370. doi:10.1007/s11121-017-0758-4

Sidebotham, P., \& Golding, J. (2001). Child maltreatment in the "Children of the Nineties"-A longitudinal study of parental risk factors. Child Abuse \& Neglect, $25,1177-1200$. doi:10.1016/S0145-2134(01)00261-7

Sidebotham, P., \& Heron, J. (2006). Child maltreatment in the "Children of the Nineties": A cohort study of risk factors. Child Abuse \& Neglect, 30 , 497-522.

Simmel, C., Merritt, D., Kim, H. M. S., \& Kim, S. (2016). An exploratory study of neglect and emotional abuse in adolescents: Classifications of caregiver risk factors. Journal of Child and Family Studies, 25, 2372 2386. doi:10.1007/s10826-016-0414-9

Simons, R. L., Whitbeck, L. B., Conger, R. D., \& Wu, C. I. (1991). Intergenerational transmission of harsh parenting. Developmental Psychology, 27, 159-171. doi:10.1037//0012-1649.27.1.159

Simons, R. L., Wu, C. I., Johnson, C., \& Conger, R. D. (1995). A test of various perspectives on the intergenerational transmission of domestic violence. Criminology, 33, 141-172.

Smith, J. A. S., \& Adler, R. G. (1991). Children hospitalized with child abuse and neglect: A case-control study. Child Abuse \& Neglect, 15, 437-445. doi:10.1016/0145-2134(91)90027-B

Smith, S. M., \& Hanson, R. (1975). Interpersonal relationships and childrearing practices in 214 parents of battered children. British Journal of Psychiatry, 127, 513-525. doi:10.1192/bjp.127.6.513 
Smith, T. D., Raman, S. R., Madigan, S., Waldman, J., \& Shouldice, M. (2018). Anogenital findings in 3569 pediatric examinations for sexual abuse/assault. Journal of Pediatric and Adolescent Gynecology, 31, 79-83. doi:10.1016/j.jpag.2017.10.006

Speizer, I. S., Goodwin, M. M., Samandari, G., Kim, S. Y., \& Clyde, M. (2008). Dimensions of child punishment in two central American countries: Guatemala and El Salvador. Revista Panamericana De Salud Publica-Pan American Journal of Public Health, 23, 247-256. doi:10.1590/ S1020-49892008000400004

Stattin, H., Janson, H., Klackenberg-Larsson, I., \& Magnusson, D. (1998). Corporal punishment in everyday life: An intergenerational perspective. In J. McCord (Ed.), Coercion and punishment in long-term perspectives (p. 315). Cambridge: Cambridge University Press.

Stith, S. M., Liu, T., Davies, L. C., Boykin, E. L., Alder, M. C., Harris, J. M., . . Dees, J. E. M. E. G. (2009). Risk factors in child maltreatment: A metaanalytic review of the literature Aggression and Violent Behavior, 14, $13-29$.

Stith, S. M., Rosen, K. H., Middleton, K. A., Busch, A. L., Lundeberg, K., \& Carlton, R. P. (2000). The intergenerational transmission of spouse abuse: A meta-analysis. Journal of Marriage and Family, 62, 640654. doi:10.1111/j.1741-3737.2000.00640.x

St-Laurent, D., Dubois-Comtois, K., Milot, T., \& Cantinotti, M. (2019). Intergenerational continuity/discontinuity of child maltreatment among low-income mother-child dyads: The roles of childhood maltreatrment characteristics, maternal psychological functioning, and family ecology. Development and Psychopathology, 31, 189-202.

Stoltenborgh, M., Bakermans-Kranenburg, M. J., Alink, L. R., \& van IJzendoorn, M. H. (2012). The universality of childhood emotional abuse: A meta-analysis of worldwide prevalence. Journal of Aggression, Maltreatment \& Trauma, 21, 870-890. doi:10.1080/10926771.2012.708014

Stoltenborgh, M., Bakermans-Kranenburg, M. J., \& van IJzendoorn, M. H. (2013). The neglect of child neglect: A meta-analytic review of the prevalence of neglect. Social Psychiatry and Psychiatric Epidemiology, 48, 345-355. doi:10.1007/s00127-012-0549-y

Stoltenborgh, M., Bakermans-Kranenburg, M. J., van IJzendoorn, M. H., \& Alink, L. R. A. (2013). Cultural-geographical differences in the occurrence of child physical abuse? A meta-analysis of global prevalence. International Journal of Psychology, 48, 81-94. doi:10.1080/ 00207594.2012.697165

Stoltenborgh, M., van IJzendoorn, M. H., Euser, E. M., \& Bakermans-Kranenburg, M. J. (2011). A global perspective on child sexual abuse: Meta-analysis of prevalence around the world. Child Maltreatment, 16, 79-101. doi:10.1177/1077559511403920

Straus, M.A. (1979). Measuring families. In H.T. Christenson (Ed.), Handbook of Marriage and the Family (pp. 335-400). Chicago: Rand McNally.

Swartz, N. E., Mercier, D. J., \& Curran, M. A. (2012). Influences of childhood abuse on parenting perspectives of pregnant cohabitors. Journal of Family Violence, 27, 597-606. doi:10.1007/s10896-012-9452-2

Tajima, E. A., \& Harachi, T. W. (2010). Parenting beliefs and physical discipline practices among Southeast Asian immigrants: Parenting in the context of cultural adaptation to the United States. Journal of Cross-Cultural Psychology, 41, 212-235.

Taplin, S., \& Mattick, R. P. (2013). Mothers in methadone treatment and their involvement with the child protection system: A replication and extension study. Child Abuse \& Neglect, 37, 500-510. doi:10.1016/j.chiabu.2013. 01.003

Taylor, J. L. (2009). Midlife impacts of adolescent parenthood. Journal of Family Issues, 30, 484-510. doi:10.1177/0192513X08329601

Thompson, R. (2006). Exploring the link between maternal history of childhood victimization and child risk of maltreatment. Journal of Trauma Practice, 5, 57-72. doi:10.1300/J189v05n02_04

Thornberry, T. P., Ireland, T. O., \& Smith, C. A. (2001). The importance of timing: The varying impact of childhood and adolescent maltreatment on multiple problem outcomes. Development and Psychopathology, 13, 957-979.

Thornberry, T. P., Knight, K. E., \& Lovegrove, P. J. (2012). Does maltreatment beget maltreatment? A systematic review of the intergenerational literature. Trauma, Violence, \& Abuse, 13, 135-152. doi:10.1177/ 1524838012447697

Thornberry, T. P., Matsuda, M., Greenman, S. J., Augustyn, M. B., Henry, K. L., Smith, C. A., \& Ireland, T. O. (2014). Adolescent risk factors for child maltreatment. Child Abuse \& Neglect, 38, 706-722.
Tomison, A. M. (1994). An evaluation of Child Abuse Decision Making in the Barwon region: A report for the Victorian Health Promotion Foundation. (Unpublished doctoral dissertation, Monash University).

Trocmé, N., Knoke, D., \& Blackstock, C. (2004). Pathways to the overrepresentation of Aboriginal children in Canada's child welfare system. Social Service Review, 78, 577-600. doi:10.1086/424545

Umeda, M., Kawakami, N., Kessler, R. C., \& Miller, E. (2015). Childhood adversities and adult use of potentially injurious physical discipline in Japan. Journal of Family Violence, 30, 515-527. doi:10.1007/s10896015-9692-z

US Department of Health and Human Services. (2014). Child Maltreatment 2014. Retrieved from http://www.acf.hhs.gov/programs/cb/researchdata-technology/statistics-research/child-maltreatment

US Natiobnal Research Council. (1993). Understanding child abuse and neglect. Washington, DC: National Academies Press.

Vachon, D. D., Krueger, R. F., Rogosch, F. A., \& Cicchetti, D. (2015). Assessment of the harmful psychiatric and behavioral effects of different forms of child maltreatment. JAMA Psychiatry, 72, 1135-1142. doi:10.1001/jamapsychiatry.2015.1792

Valentine, J. C., Pigott, T. D., \& Rothstein, H. R. (2010). How many studies do you need? A primer on statistical power for meta-analysis. Journal of Educational and Behavioral Statistics, 35, 215-247. doi:10.3102/ 1076998609346961

Valentino, K., Nuttall, A. K., Comas, M., Borkowski, J. G., \& Akai, C. E. (2012). Intergenerational continuity of child abuse among adolescent mothers: Authoritarian parenting, community violence, and race. Child Maltreatment, 17, 172-181. doi:10.1177/1077559511434945

Veracruz, E. R. (2018). Examining the intergenerational transmission of child physical abuse in a U.S. sample. Dissertation Abstracts International: Section B: The Sciences and Engineering, 78.

Verhage, M., Schuengel, C., Madigan, S., Fearon, R., Oosterman, M., Cassibba, R., . . \& \& Van IJzendoorn, M. (2016). Narrowing the transmission gap: A synthesis of three decades of research on intergenerational transmission of attachment. Psychological Bulletin.,142(4), 337-366. doi:10.1037/bul0000038

Wang, M. F., \& Xing, X. P. (2014). Intergenerational transmission of parental corporal punishment in China: The moderating role of spouse's corporal punishment. Journal of Family Violence, 29, 119-128.

Wearick-Silva, L. E., Tractenberg, S. G., Levandowski, M. L., Viola, T. W., Pires, J. M., \& Grassi-Oliveira, R. (2014). Mothers who were sexually abused during childhood are more likely to have a child victim of sexual violence. Trends in Psychiatry and Psychotherapy, 36, 119-122. doi:10.1590/2237-6089-2013-0054

Webster-Stratton, C. (1985). Comparison of abusive and nonabusive families with conduct-disordered children. American Journal of Orthopsychiatry, 55, 59-69. doi:10.1111/j.1939-0025.1985.tb03421.x

Wekerle, C., Wall, A. M., Leung, E., \& Trocmé, N. (2007). Cumulative stress and substantiated maltreatment: The importance of caregiver vulnerability and adult partner violence. Child Abuse \& Neglect, 31, 427-443. doi:10.1016/j.chiabu.2007.03.001

Whipple, E. E., \& Websterstratton, C. (1991). The role of parental stress in physically abusive families. Child Abuse \& Neglect, 15, 279-291. doi:10.1016/0145-2134(91)90072-L

Widom, C. S. (1989). The cycle of violence. Science, 244, 160-166. doi:10.1126/science.2704995

Widom, C. S., Czaja, S. J., \& DuMont, K. A. (2015). Intergenerational transmission of child abuse and neglect: Real or detection bias? Science, 347 1480-1485. doi:10.1126/science.1259917

Widom, C. S., \& Wilson, H. W. (2015). Intergenerational tranmission of violence. In J. Lindert \& I. Levav (Eds.), Violence and mental health: Its manifold faces (pp. 27-45). Dordrecht: Springer.

Wilson, H. W., Stover, C. S., \& Berkowitz, S. J. (2009). Research Review: The relationship between childhood violence exposure and juvenile antisocial behavior: A meta-analytic review. Journal of Child Psychology and Psychiatry, 50, 769-779.

Wolock, I., \& Horowitz, B. (1979). Child maltreatment and material deprivation among AFDC-recipient families. Social Service Review, 53, 175194. doi: $10.1086 / 643725$

World Health Organization. (1999). Report of the Consultation on Child Abuse Prevention, 29-31, March 1999. Geneva: Author.

World Health Organization. (2001). Child abuse and neglect by parents and other caregivers. In World Health Organization, World report on violence and health (pp.57-86). Geneva: Author. 
Zajac, K. (2009). Caregivers' histories of childhood abuse: Effects on children's behavior problems and reactivity to stress. Dissertation Abstracts International: Section B: The Sciences and Engineering, 70, 5873.

Zalewski, M., Cyranowski, J. M., Cheng, Y., \& Swartz, H. A. (2013). Role of maternal childhood trauma on parenting among depressed mothers of psychiatrically ill children. Depression and Anxiety, 30, 792-799. doi:10.1002/da.22116
Zavala, E. (2013). Testing the link between child maltreatment and family violence among police officers. Crime \& Delinquency, 59, 468-483. doi:10.1177/0011128710389584

Zuravin, S., McMillen, C., DePanfilis, D., \& Risley-Curtiss, C. (1996). The intergenerational cycle of child maltreatment: Continuity versus discontinuity. Journal of Interpersonal Violence, 11, 315-334. doi:10.1177/ 088626096011003001

\section{Appendix A}

\section{Database: Ovid MEDLINE(R) Epub Ahead of Print, In-Process \& Other Non-Indexed Citations, Ovid MEDLINE(R) Daily, and Ovid MEDLINE(R) $<1946$ to Present $>$}

Search strategy

1 child abuse/ or child abuse, sexual/ (27662)

2 incest/ (1615)

3 Rape/ (5976)

4 Shaken Baby Syndrome/ (514)

5 Child, Abandoned/ (502)

6 ((child* or physical or sex* or emotional or verbal or psychological) adj6 (violen* or abus* or maltreat* or mistreat*)).mp. (54633)

7 (incest* or rape*).mp. (15341)

8 (neglect* $^{*}$ or trauma*).mp. (419064)

9 or/1-8 (470986)

10 (intergeneration* adj10 (abus* or trauma* or maltreat* or mistreat* or violen* or transmission*)).mp. (1276)
11 (transgeneration* adj10 (abus* or trauma* or maltreat* or mistreat* or violen* or transmission*)).mp. (321)

12 ((cycle* or cyclical) adj6 (abus* or trauma* or maltreat* or mistreat* or violen*)).mp. (649)

13 (generation* adj10 (abus* or trauma* or maltreat* or mistreat* or violen* or transmission*)).mp. (3320)

14 or/10-13 (5263)

159 and 14 (1442)

16 limit 15 to "all child (0 to 18 years)" (649)

17 (infan* or newborn* or new-born* or neonat* or baby or babies or child* or youth or kid or kids or toddler* or boy* or girl* or adolescen* or teen* or juvenile* or pediatric*).mp. (3993491)

189 and 14 and 17 (957)

1916 or $18(957)$

\section{Appendix B}

Study characteristics for all studies included in the meta-analysis

\begin{tabular}{|c|c|c|c|c|c|c|}
\hline \multirow[b]{2}{*}{ Article } & \multirow[b]{2}{*}{$N$} & \multirow[b]{2}{*}{$\operatorname{Age}^{\mathrm{a}}(\mathrm{G} 2)$} & \multicolumn{2}{|c|}{ Maltreatment measures } & \multicolumn{2}{|c|}{ Maltreatment type } \\
\hline & & & $\mathrm{G} 2$ & G3 & $\mathrm{G} 2$ & G3 \\
\hline Abolfotouh (2009) & 153 & 10.77 & NV-I & NV-I & PH & $\mathrm{PH}$ \\
\hline \multicolumn{7}{|l|}{ Adamson (1997) } \\
\hline G2 males & 89 & 48.90 & PCCTS* & PCCTS* & MT & MT \\
\hline G2 females & 161 & 47.30 & PCCTS* & PCCTS* & MT & MT \\
\hline Altemeier (1982) & 1400 & 2.88 & NV-I & $\mathrm{CPS}^{+}$ & $\mathrm{N}$ & PH \\
\hline Appleyard (2011) & 499 & 2.17 & PCCTS* & $\mathrm{CPS}^{+}$ & $\mathrm{PH}, \mathrm{SX}, \mathrm{N}$ & MT \\
\hline Avery (2002) & 425 & 7.90 & NV-Q & $\mathrm{CPS}^{+}$ & SX & SX \\
\hline Bailey (2007) & 363 & 11.90 & NV-I & NV-I & SX & SX \\
\hline Baldwin (1975) & 51 & 0.42 & NV-CR & $\mathrm{CPS}^{+}$ & MT & MT \\
\hline Ball (2009) & 414 & - & $\mathrm{CTS}^{*}$ & CTS* & $\mathrm{PH}$ & $\mathrm{PH}$ \\
\hline Banyard (1997) & 430 & - & NV-Q & PCCTS* & $\mathrm{PH}, \mathrm{SX}, \mathrm{N}$ & $\mathrm{PH}$ \\
\hline Banyard (2003) & 152 & 11.95 & $\mathrm{CTS}^{*}, \mathrm{HR}^{+}$ & $\mathrm{CTS}^{*} / \mathrm{CPS}^{+}$ & $\mathrm{PH}, \mathrm{SX}$ & $\mathrm{PH}, \mathrm{N}, \mathrm{MT}$ \\
\hline Barrett (2009) & 477 & 9.47 & NV-I & PCCTS* & $\mathrm{PH}, \mathrm{N}$ & EMP, SX, MT \\
\hline Bartlett (2017) & 471 & 4.80 & $\mathrm{CPS}^{+}$ & $\mathrm{CPS}^{+}$ & $\mathrm{MT}, \mathrm{N}$ & $\mathrm{MT}, \mathrm{N}$ \\
\hline Beckerman (2017) & 53 & 3.70 & CTQ* & PS*/CTS* & MT & MT \\
\hline Ben-David (2015) & 6935 & 5.50 & $\mathrm{CPS}^{+}$ & $\mathrm{CPS}^{+}$ & $\mathrm{MT}, \mathrm{N}$ & MT \\
\hline Bert (2009) & 681 & 0.50 & CTQ* & PSEQ* & EMP, PH, SX & MT \\
\hline Bosquet Enlow (2017) & 179 & 4.71 & NV-I & $\mathrm{CPS}^{+}, \mathrm{OBS}$ & MT & MT \\
\hline Brodsky (2008) & 507 & 22.80 & $\mathrm{CEQ}^{*}$ & CARE* & $\mathrm{PH}, \mathrm{SX}$ & $\mathrm{PH}, \mathrm{SX}$ \\
\hline Caykoylu (2011) & 1202 & - & NV-I & NV-I & $\mathrm{PH}$ & $\mathrm{PH}$ \\
\hline Choi (2018) & 1016 & 12.00 & CTQ* & CTQ* & MT & MT \\
\hline Cicchetti (2006) & 189 & 1.11 & CTQ* & $\mathrm{CPS}^{+}$ & $\mathrm{SX}$ & MT \\
\hline Clément (2005) & 929 & 7.33 & NV-I & PCCTS* & MT & PH \\
\hline Cohen (2008) & 176 & 12.00 & LEC $^{*}$ & PCCTS* & $\mathrm{PH}, \mathrm{SX}$ & PH, EMP \\
\hline Cole (1992) & 59 & 9.00 & NV-I & PDI* & SX & PH, EMP \\
\hline
\end{tabular}


(cont.)

\begin{tabular}{|c|c|c|c|c|c|c|}
\hline \multirow[b]{2}{*}{ Article } & \multirow[b]{2}{*}{$N$} & \multirow[b]{2}{*}{$\operatorname{Age}^{a}(G 2)$} & \multicolumn{2}{|c|}{ Maltreatment measures } & \multicolumn{2}{|c|}{ Maltreatment type } \\
\hline & & & G2 & G3 & G2 & G3 \\
\hline Coohey (1997) & 229 & - & CTS* & $\mathrm{CPS}^{+}$ & PH & $\mathrm{PH}$ \\
\hline Cort (2011) & 104 & 11.00 & CTQ* & $\mathrm{CPS}^{+}$ & MT & MT \\
\hline Covell (1995) & 32 & 4.00 & NV-Q & NV-Q & $\mathrm{PH}, \mathrm{N}$ & PH, EMP \\
\hline Crombach (2015) & 173 & - & NV-I & NV-I & MT & MT \\
\hline DeBruyn (1992) & 190 & 8.72 & NV-I & $\mathrm{HP}^{+}, \mathrm{NV}-\mathrm{I}$ & MT & MT \\
\hline \multicolumn{7}{|l|}{ Dias (2014) } \\
\hline War & 91 & 33.00 & CTQ* & $\mathrm{CTQ}^{*}$ & ALL & ALL \\
\hline War and PTSD & 56 & 33.00 & $\mathrm{CTQ}^{*}$ & CTQ* & ALL & ALL \\
\hline No War & 41 & 33.00 & CTQ* & CTQ* & ALL & ALL \\
\hline Dietz (2000) & 956 & 8.32 & NV-I & PCCTS* & $\mathrm{PH}$ & $\mathrm{PH}$ \\
\hline DiLillo (2000) & 290 & 3.19 & NV-I & NV-I & SX & $\mathrm{PH}$ \\
\hline Disbrow (1977) & 83 & - & NV-I & $\mathrm{CPS}^{+}, \mathrm{OBS}$ & MT & $\mathrm{PH}, \mathrm{N}, \mathrm{MT}$ \\
\hline Dixon (2005) & 4351 & 1.08 & NV-I & $\mathrm{CPS}^{+}, \mathrm{OBS}$ & MT & MT \\
\hline Dubowitz (1987) & 115 & - & NV-I & $\mathrm{HR}$ & PA & MT \\
\hline Dubowitz (2001) & 244 & 4.88 & NV-Q & CTS* & MT & MT \\
\hline \multicolumn{7}{|l|}{ Duckworth (1997) } \\
\hline Females & 64 & - & CTS*, PSY* & $\begin{array}{c}\text { V-PARQ, } \\
\text { CTS* } \\
\text { V-PARQ, }\end{array}$ & PH, EMP & PH, EMP \\
\hline Males & 19 & - & $\mathrm{CTS}^{*}, \mathrm{PSY}^{*}$ & CTS* & PH, EMP & PH, EMP \\
\hline Duhamel (2004) & 41 & 9.00 & AEIII* & PCCTS* & $\mathrm{PH}$ & $\mathrm{PH}$ \\
\hline Dworsky (2015) & 1938 & 1.20 & $\mathrm{CPS}^{+}$ & $\mathrm{CPS}^{+}$ & $\mathrm{PH}, \mathrm{SX}, \mathrm{N}$ & MT \\
\hline Egeland (1996) & 244 & 4.25 & NV-I & OBS & MT & MT \\
\hline Esaki (2008) & 477 & 8.00 & LONGSCAN* & $\mathrm{CPS}^{+}$ & MT & MT \\
\hline Éthier (1995) & 80 & 4.55 & NV-I & $\mathrm{CPS}^{+}$ & PH, N EMP & $\mathrm{N}$ \\
\hline Falbo (2004) & 190 & - & NV-I & NV-I & MT & $\mathrm{PH}$ \\
\hline Ferrari (2002) & 150 & - & CTQ* & CTS* & MT & PH, EMP \\
\hline Finkelhor (1997) & 998 & 8.27 & NV-I & NV-I & $\mathrm{SX}$ & $\mathrm{SX}$ \\
\hline Folsom (2003) & 436 & 5.55 & NV-I, $\mathrm{CR}^{+}$ & $\mathrm{CPS}^{+}$ & MT & MT \\
\hline Francis (2008) & 49 & 6.00 & CTQ* & $\mathrm{CPS}^{+}$ & MT & PA \\
\hline Fujiwara (2010) & 304 & 7.80 & CTQ* & NV-Q & ALL & PH, N, EMP \\
\hline Fuller (2003) & 306 & 7.00 & CTS* & CTS* & $\mathrm{PH}$ & MT \\
\hline Gage (2010) & 7724 & 8.50 & NV-Q & NV-Q & $\mathrm{PH}$ & $\mathrm{PH}$ \\
\hline Glasser (2001) & 747 & & $\mathrm{CR}^{+}$ & $\mathrm{CR}^{+}$ & SX & SX \\
\hline Goodwin (1981) & 591 & 8.50 & $\mathrm{SSQ}^{*}, \mathrm{NV}-\mathrm{I}$ & $\mathrm{CPS}^{+}, \mathrm{NV}-\mathrm{I}$ & SX & MT \\
\hline Grusec (1991) & 32 & 4.00 & NV-I & NV-I & PH, EMP & PH, EMP \\
\hline \multicolumn{7}{|l|}{ Haapasalo (1999) } \\
\hline CPS involved & 25 & 12.68 & NV-I & $\mathrm{CR}^{+}, \mathrm{NV}-\mathrm{I}$ & PH, EMP & PH, EMP \\
\hline CPS not involved & 25 & 11.88 & NV-I & $\mathrm{CR}^{+}, \mathrm{NV}-\mathrm{I}$ & PH, EMP & PH, EMP \\
\hline Healy (1991) & 27 & - & $\mathrm{CR}^{+}$ & $\mathrm{CPS}^{+}$ & $\mathrm{PH}, \mathrm{SX}$ & $\mathrm{PH}$ \\
\hline Hemenway (1994) & 309 & - & NV-I & NV-I & EMP, MT & EMP, MT \\
\hline Herrenkohl (1983) & 529 & - & NV-I & NV-I & $\mathrm{PH}$ & $\mathrm{PH}$ \\
\hline Herrenkohl (2013) & 268 & 1.83 & NV-I & NV-I & $\mathrm{PH}$ & $\mathrm{PH}$ \\
\hline Heyman (2002) & 1244 & - & CTS* & CTS* & $\mathrm{PH}$ & $\mathrm{PH}$ \\
\hline Hunter (1979) & 259 & 0.77 & NV-I & $\mathrm{CPS}^{+}$ & MT & MT \\
\hline Isumi (2016) & 4297 & 0.42 & ACES* & NV-Q & PH, N, EMP & $\mathrm{PH}$ \\
\hline Jackson (1999) & 1000 & 8.40 & PCCTS* & NV-I & $\mathrm{PH}, \mathrm{SX}$ & PH, EMP \\
\hline Jaffee (2013) & 1116 & 9.50 & CTQ* & OBS, NV-I & MT & $\mathrm{PH}$ \\
\hline Jamal (2011) & 200 & 9.10 & NV-I & PCCTS* & $\mathrm{PH}$ & PH, EMP \\
\hline Joo $(2008)$ & 130 & 9.62 & EPAB* & NV-Q & ALL exc. SX & ALL exc. SX \\
\hline Kim, K. (2007) & 120 & 11.00 & MDHQ* & $\mathrm{CPS}^{+}$ & PH, SX, EMP & SX \\
\hline Kim, K. (2010) & 127 & 11.10 & MDHQ* & $\mathrm{CPS}^{+}$ & $\mathrm{SX}, \mathrm{MT}$ & SX, MT \\
\hline Kim, J. (2009) & 2977 & 1.50 & NV-I & NV-I & $\mathrm{PH}, \mathrm{N}$ & $\mathrm{PH}, \mathrm{N}$ \\
\hline Kim, J. (2017) & 2875 & 9.00 & NV-I & NV-I & $\mathrm{PH}$ & $\mathrm{PH}$ \\
\hline Kim, H. (2010) & 488 & 2.00 & CTS* & PCCTS* & MT & MT \\
\hline Kotelchuk (1982) & 402 & 2.00 & NV-Q & $\mathrm{HR}^{+}$ & $\mathrm{PH}$ & MT \\
\hline Kovan (2009) & 26 & 2.00 & OBS & OBS & EMP & EMP \\
\hline Leifer (2004) & 199 & 7.00 & NV-I & $\mathrm{CPS}^{+}$ & MT & SX \\
\hline Lesnik-Oberstein (1995) & 172 & 1.90 & NV-Q & $\mathrm{CR}^{+}$ & MT & EMP \\
\hline
\end{tabular}


(cont.)

\begin{tabular}{|c|c|c|c|c|c|c|}
\hline \multirow[b]{2}{*}{ Article } & \multirow[b]{2}{*}{$N$} & \multirow[b]{2}{*}{$\operatorname{Age}^{\mathrm{a}}(\mathrm{G} 2)$} & \multicolumn{2}{|c|}{ Maltreatment measures } & \multicolumn{2}{|c|}{ Maltreatment type } \\
\hline & & & $\mathrm{G} 2$ & G3 & $\mathrm{G} 2$ & G3 \\
\hline \multicolumn{7}{|l|}{ Libby (2008) } \\
\hline Southwestern & 1049 & - & NV-I & NV-I & PH, SX & $\mathrm{N}$ \\
\hline Northern & 1172 & - & NV-I & NV-I & $\mathrm{PH}, \mathrm{SX}$ & $\mathrm{N}$ \\
\hline Lukek (2015) & 25 & 9.60 & NV-Q & NV-Q & PH, EMP & PH, EMP \\
\hline Macias (2004) & 63 & 7.50 & PSI* & TSCE* & MT & $\mathrm{MT}$ \\
\hline Maida (2005) & 89 & 7.00 & NV-Q & $\mathrm{CR}^{+}$ & SX & $\mathrm{MT}, \mathrm{SX}$ \\
\hline Massé (1994) & 209 & 6.00 & NV-I & $\mathrm{CPS}^{+}$ & MT, SX & MT \\
\hline Matos (2014) & 277 & 7.30 & NV-Q & $\mathrm{CPS}^{+}$ & MT & N, MT, EMP \\
\hline McCloskey (2000) & 171 & 9.00 & SES* & $\mathrm{CR}^{+}, \mathrm{NV}-\mathrm{I}$ & $\mathrm{SX}$ & SX \\
\hline Medley (2009) & 4141 & - & NCS* & NV-I & $\mathrm{PH}, \mathrm{MT}, \mathrm{SX}$ & $\mathrm{PH}$ \\
\hline Milaniak (2015) & 1196 & 2.00 & $\mathrm{OR}^{+}$ & $\mathrm{CPS}^{+}$ & MT & MT \\
\hline Militza (2010) & 1375 & 14.50 & NV-I & NV-I & $\mathrm{PH}, \mathrm{N}$ & $\mathrm{PH}, \mathrm{N}$ \\
\hline Miller (1999) & 165 & 9.90 & CTS*, NV-I & CTS* & $\mathrm{PH}, \mathrm{SX}$ & PH, EMP \\
\hline Miller (2000) & 504 & - & API* & API* & $\mathrm{SX}, \mathrm{PH}, \mathrm{MT}$ & MT \\
\hline Mirabella-Beck (1999) & 222 & 0.82 & NV-Q & CTS/API/CPS ${ }^{+}$ & MT & PH, MT, EMP \\
\hline Muller (1995) & 732 & 18.00 & $\mathrm{CTS}^{*}$ & $\mathrm{CTS}^{*}$ & $\mathrm{PH}$ & $\mathrm{PH}$ \\
\hline Murphy-Cowan (1999) & 371 & 5.41 & NV-Q & NV-Q & PH, EMP & $\mathrm{PH}$ \\
\hline Narayan (2017) & 92 & 5.86 & $\mathrm{ACES} *$ & $\mathrm{ACES} *$ & MT & MT \\
\hline Newcomb (2001) & 100 & - & $\mathrm{CTQ}^{*}$ & PARQ* & $\mathrm{MT}, \mathrm{SX}, \mathrm{N}$ & MT \\
\hline Ney (1988) & 65 & 8.50 & $\mathrm{PBI}^{*}$ & CA, NV-Q & ALL exc. MT & ALL exc. MT \\
\hline \multicolumn{7}{|l|}{ Noll (2009) } \\
\hline $\mathrm{G} 1$ to $\mathrm{G} 2$ & 128 & 11.11 & $\mathrm{CPS}^{+}, \mathrm{NV}-\mathrm{I}$ & $\mathrm{CPS}^{+}, \mathrm{NV}-\mathrm{I}$ & SX & SX \\
\hline $\mathrm{G} 2$ to $\mathrm{G} 3$ & 135 & 4.16 & $\mathrm{CPS}^{+}$ & $\mathrm{CPS}^{+}$ & SX & MT \\
\hline Oates (1998) & 132 & - & PBI* & $\mathrm{CR}^{+}$ & SX & SX \\
\hline Özcan (2016) & 126 & 22.05 & $\mathrm{CTQ}^{*}$ & $\mathrm{CTQ}^{*}$ & ALL exc. $\mathrm{N}$ & ALL exc. $\mathrm{N}$ \\
\hline Pears (2001) & 109 & 20.75 & AEIII* & AEIII* & $\mathrm{PH}$ & $\mathrm{PH}$ \\
\hline Peltonen (2014) & 2716 & 6.00 & NV-Q & CTS* & $\mathrm{PH}$ & $\mathrm{PH}$ \\
\hline Perepletchikova (2012) & 99 & - & $\mathrm{CTQ}^{*}$ & $\mathrm{CPS}^{+}$ & ALL & MT \\
\hline Pérez (2003) & 142 & 19.00 & $\mathrm{CHQ}^{*}$ & $\mathrm{CHQ}^{*}$ & MT & MT \\
\hline Plant (2013) & 114 & 11.00 & OBS; NV-I & $\mathrm{CA}^{+}$ & MT & MT \\
\hline Putnam- Hornstein (2015) & 85084 & 2.50 & $\mathrm{CPS}^{+}$ & $\mathrm{CPS}^{+}$ & MT & MT \\
\hline Ramírez (2011) & 1089 & 8.50 & NV-I & NV-I & MT & $\mathrm{MT}, \mathrm{SX}$ \\
\hline Renner (2006) & 1005 & 7.40 & NV-I & $\mathrm{CPS}^{+}$ & $\mathrm{PH}, \mathrm{SX}, \mathrm{N}$ & $\mathrm{PH}, \mathrm{MT}, \mathrm{N}$ \\
\hline Rijlaarsdam (2014) & 3212 & 3.05 & $\mathrm{CTQ}^{*}$ & PCCTS* & MT & MT, EMP \\
\hline Rikić (2017) & 118 & 5.00 & $\mathrm{CAQ}^{*}$ & $\mathrm{CAQ}^{*}$ & EMP, PH, MT & EMP. PH, MT \\
\hline Rodriguez (1999) & 99 & - & NV-Q & NV-SR & $\mathrm{PH}$ & $\mathrm{PH}$ \\
\hline Romero (2005) & 300 & 10.00 & CTS* & CTS* & MT & PH, EMP \\
\hline Sahin (2011) & 275 & - & NV-I & NV-I & $\mathrm{PH}$ & $\mathrm{PH}$ \\
\hline Saile (2014) & 283 & 9.01 & PCCTS* & PCCTS* & MT & MT \\
\hline Salzinger (1992) & 191 & 10.20 & NV-I, CPS ${ }^{+}$ & $\mathrm{CR}^{+}, \mathrm{NV}-\mathrm{I}$ & $\mathrm{PH}$ & $\mathrm{PH}$ \\
\hline Scaramella (2003) & 75 & 2.40 & OBS & OBS & MT & MT \\
\hline Schluter (2011) & 742 & 1.50 & EASEPI* & PBC* & $\mathrm{PH}$ & $\mathrm{PH}$ \\
\hline Seay (2016) & 204 & 4.00 & PCSYSR* & PRCMR* & EMP & MT \\
\hline Sidebotham (2001) & 14138 & 2.53 & NV-Q & $\mathrm{CPS}^{+}$ & PH, SX, EMP & MT \\
\hline Sidebotham (2006) & 14256 & 2.53 & NV-Q & $\mathrm{CPS}^{+}$ & $\mathrm{MT}$ & MT \\
\hline Simmel (2016) & 268 & 14.1 & NV-I & $\mathrm{CPS}^{+}$ & MT & N, EMP \\
\hline \multicolumn{7}{|l|}{ Simons (1991) } \\
\hline Female G3 & 236 & 12.70 & CTS* & CTS* & MT & MT \\
\hline Male G3 & 215 & 12.70 & CTS* & CTS* & MT & MT \\
\hline Simons (1995) & 333 & 12.70 & CTS* & CTS* & $\mathrm{PH}$ & $\mathrm{PH}$ \\
\hline Smith (1991) & 90 & 1.42 & NV-I & $\mathrm{HR}^{+}$ & $\mathrm{PH}$ & $\mathrm{PH}$ \\
\hline Smith (1975) & 187 & 2.50 & NV-I & $\mathrm{HR}^{+}$ & PH, MT, EMP & $\mathrm{PH}$ \\
\hline Speizer (2008) & 1448 & 9.00 & NV-I & NV-I & PH, EMP & PH, EMP \\
\hline \multicolumn{7}{|l|}{ Stattin (1998) } \\
\hline \multicolumn{7}{|l|}{$\mathrm{G} 1 / \mathrm{G} 2$} \\
\hline females & 90 & 9.92 & NV-I & NV-I & PH & $\mathrm{PH}$ \\
\hline G1/G2 males & 122 & 9.00 & NV-I & NV-I & $\mathrm{PH}$ & $\mathrm{PH}$ \\
\hline \multicolumn{7}{|l|}{ Tajima (2010) } \\
\hline Cambodian & 153 & 13.20 & NV-I & CTS* & $\mathrm{PH}$ & $\mathrm{PH}$ \\
\hline Vietnamese & 155 & 13.20 & NV-I & CTS* & $\mathrm{PH}$ & $\mathrm{PH}$ \\
\hline
\end{tabular}


(cont.)

\begin{tabular}{|c|c|c|c|c|c|c|}
\hline \multirow[b]{2}{*}{ Article } & \multirow[b]{2}{*}{$N$} & \multirow[b]{2}{*}{$\operatorname{Age}^{a}(G 2)$} & \multicolumn{2}{|c|}{ Maltreatment measures } & \multicolumn{2}{|c|}{ Maltreatment type } \\
\hline & & & G2 & G3 & G2 & G3 \\
\hline Taplin (2013) & 171 & 8.00 & CECAQ* & $\mathrm{CPS}^{+}$ & $\mathrm{PH}, \mathrm{SX}, \mathrm{N}$ & MT \\
\hline Thompson (2006) & 220 & 0.83 & LONGSCAN* & $\mathrm{CPS}^{+}$ & PH, SX & MT \\
\hline Thornberry (2014) & 816 & 13.55 & $\mathrm{CPS}^{+}$ & $\mathrm{CPS}^{+}$ & MT & MT \\
\hline Tomison (1994) & 179 & 8.51 & $\mathrm{CPS}^{+}$ & $\mathrm{CR}^{+}$ & MT & MT \\
\hline Trocmé (2004) & 2891 & 7.50 & $\mathrm{CIS}^{+} 8^{+}$ & $\mathrm{CPS}^{+}$ & MT & MT \\
\hline Umeda (2015) & 1186 & 5.00 & CTS* & CTS* & PH, SX, N & $\mathrm{PH}$ \\
\hline Valentino (2012) & 70 & 18.00 & CTQ* & CTQ* $^{*}$ & MT & MT \\
\hline Veracruz (2018) & 4102 & - & NCS* & NCS-R* & ALL exc. EMP & $\mathrm{PH}$ \\
\hline Wang (2014) & 761 & 9.73 & PCCTS* & PCCTS* & PH & $\mathrm{PH}$ \\
\hline Wearick-Silva (2014) & 123 & - & CTQ* & $\mathrm{CPS}^{+}$ & ALL & SX \\
\hline Webster-Stratton (1985) & 40 & 4.79 & NV-Q & $\mathrm{CPS}^{+}$ & MT & $\mathrm{PH}, \mathrm{MT}$ \\
\hline Wekerle (2007) & 7672 & 7.50 & $\mathrm{CPS}^{+}$ & $\mathrm{CPS}^{+}$ & MT & $\mathrm{PH}, \mathrm{SX}, \mathrm{N}$ \\
\hline Whipple (1991) & 123 & 4.54 & NV-I & $\mathrm{CPS}^{+}, \mathrm{OBS}$ & MT & $\mathrm{PH}$ \\
\hline Widom (2015) & 1147 & 22.80 & $\mathrm{CPS}^{+}$ & $\begin{array}{l}\mathrm{CPS}^{+}, \mathrm{CTS}^{*} \\
\mathrm{CEQ}^{*}\end{array}$ & $\begin{array}{l}\text { ALL exc. } \\
\text { EMP }\end{array}$ & $\begin{array}{l}\text { ALL exc. } \\
\text { EMP }\end{array}$ \\
\hline Wolock (1979) & 519 & - & NV-I & $\mathrm{CPS}^{+}$ & $\mathrm{PH}, \mathrm{N}$ & MT \\
\hline Zajac (2009) & 198 & 13.00 & SLESQ* & CTS* & $\mathrm{PH}, \mathrm{SX}$ & PH, EMP \\
\hline Zalewski (2013) & 95 & 15.05 & $\mathrm{CTQ}^{*}$ & PBI* & $\mathrm{PH}, \mathrm{N}, \mathrm{EMP}$ & EMP \\
\hline Zavala (2013) & 860 & - & NV-Q & NV-Q & $\mathrm{PH}$ & $\mathrm{PH}$ \\
\hline Zuravin (1996) & 213 & 6.00 & NV-Q & $\mathrm{CPS}^{+}$ & ALL exc. EMP & MT \\
\hline
\end{tabular}

Note: Measurement type: CA, clinical assessment; CPS, Child Protective Service records; CR, case review; CREC, court records; HR, hospital records; I, interview; NV, nonvalidated measure; OBS, observer report; OR, offender records; Q, questionnaire. Measurement instrument: AAPI, Adult-Adolescent Parenting Inventory; ACES, adverse childhood experiences; AEIII, Assessing Environments-III; AMP, About My Parent (History of Neglect) Scale; API, Abuse and Perpetration Inventory; ASI, Addiction Severity Index; BDPAI, Brofenbrenner-Devereux Parental Activity Inventory; CARE, Child and Adolescent Review of Experiences; CAQ, Child Abuse Questionnaire; CECAQ, Childhood Experience of Care and Abuse Questionnaire; CEQ, Childhood Experiences Questionnaire; CHQ, Childhood History Questionnaire; CIS98, 1998 Canadian Incidence Study of Reported Child Maltreatment; CMHI, Cook-Medley Hostility Scale; CSAI, Childhood Sexual Abuse Interview; CTQ, Childhood Trauma Questionnaire; CTS, Conflict Tactics Scale; EASEPI, Exposure to Abusive and Supportive Environments Parenting Inventory; EPAB, Emotional and Physical Abuse Questionnaire; LEC, Life Events Checklist; LONGSCAN, Longitudinal Studies of Child Abuse and Neglect; MDHQ, Mothers' Developmental History Questionnaire; NCS, National Comorbidity Survey; PARQ, Parental Acceptance and Rejection Questionnaire; PBC, Parent Behaviour Checklist; PBI, Parental Bonding Instrument; PCCTS, Parent-Child Conflict Tactics Scale; PCRQ, Parent-Child Relationship Questionnaire; PCSYSR, Psychological Control Scale Youth Self-Report; PDI, Parenting Dimensions Inventory; PPS, Parental Punitiveness Scale; PRCMR, Parental Responses to Child Misbehavior-Revised; PS, Parenting Scale; PSI, Parenting Stress Index; PSY, Psychological Maltreatment Scale; SES, Sexual Experiences Survey; SLESQ, Stressful Life Events Screening Questionnaire; SSQ, Sexual Stress Questionnaire; THQ, Trauma History Questionnaire. Maltreatment type: EMP, emotional/psychological maltreatment; MT, multitype maltreatment; N, neglect; PH, physical maltreatment; SX, sexual abuse; ALL, each of the maltreatment types previously listed; DV, domestic violence. Study design: EC, epidemiological cross-sectional study design; IT, intervention study design; L, longitudinal study design; PC, prospective cohort study design; RC, retrospective cross-sectional study design. *Validated instrument. ${ }^{+}$Official record. ' If two ages are provided, the study was longitudinal and the age reported is the age of G3 at the time maltreatment was reported. 